\title{
Reformatted Data Sets Used in the Cooperative LACSD/USGS Palos Verdes Flow Study, 2000-2008
}

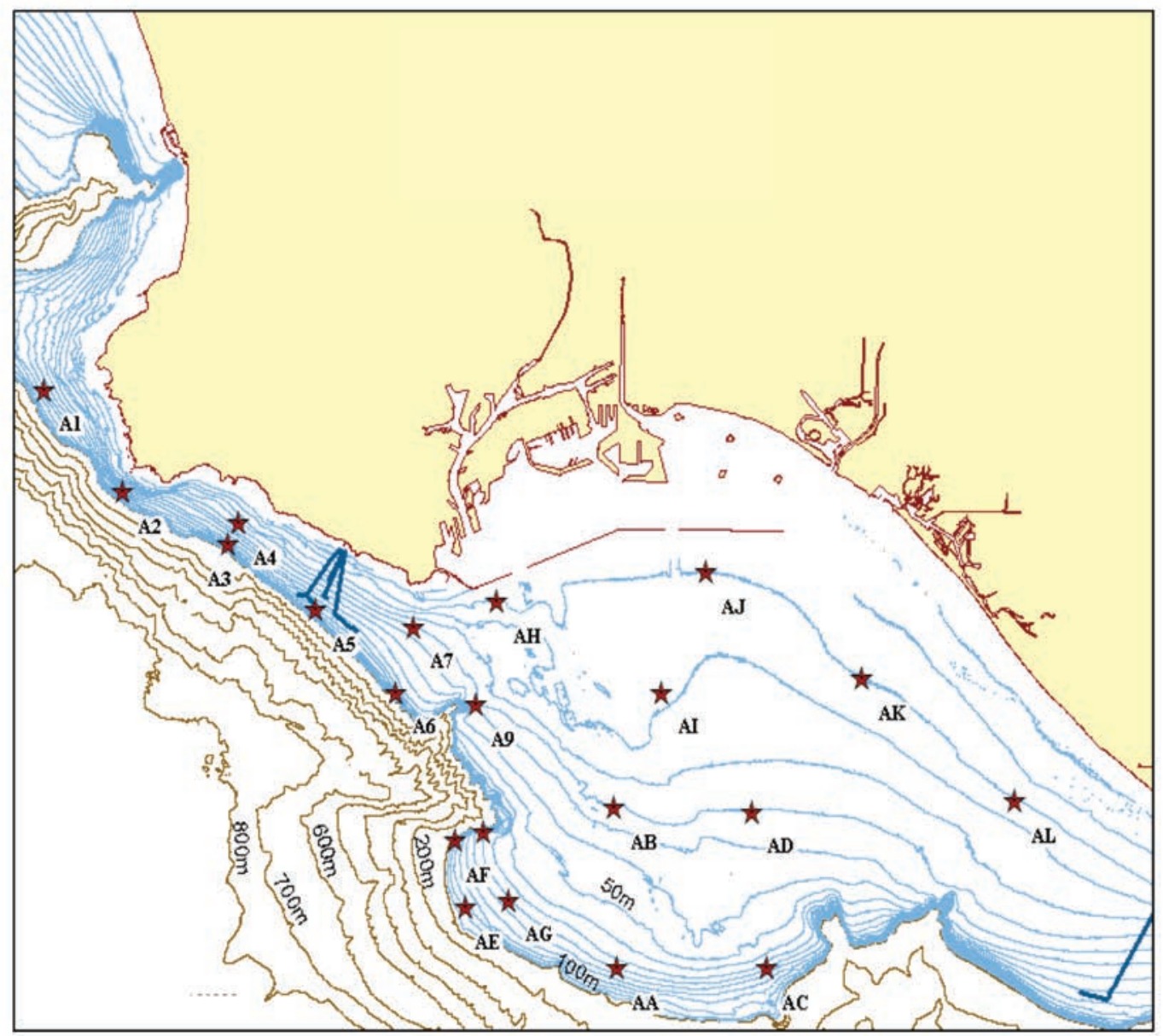

Open-File Report 2010-1253

U.S. Department of the Interior

U.S. Geological Survey 
This page intentionally left blank 
Reformatted Data Sets Used in the Cooperative LACSD/USGS Palos Verdes Flow Study, 2000-2008

By Todd Anderson, Kurt J. Rosenberger, and Anne L. Gartner

Open-File Report 2010-1253

U.S. Department of the Interior

U.S. Geological Survey 


\section{U.S. Department of the Interior \\ KEN SALAZAR, Secretary}

\section{U.S. Geological Survey \\ Marcia K. McNutt, Director}

U.S. Geological Survey, Reston, Virginia: 2012

For more information on the USGS-the Federal source for science about the Earth,

its natural and living resources, natural hazards, and the environment-visit

http://www.usgs.gov or call 1-888-ASK-USGS

For an overview of USGS information products, including maps, imagery, and publications, visit $h$ ttp://www.usgs.gov/pubprod

To order this and other USGS information products, visit http://store.usgs.gov

Suggested citation:

Anderson, T., Rosenberger, K.J., and Gartner, A.L., 2012, Reformatted data sets used in the Cooperative LACSD/USGS Palos Verdes Flow Study, 2000-2008: U.S. Geological Survey Open-File Report 2010-1253, 45 p. [available on the World Wide Web at http://pubs.usgs.gov/of/2010/1253/].

Any use of trade, product, or firm names is for descriptive purposes only and does not imply endorsement by the U.S. Government.

Although this report is in the public domain, permission must be secured from the individual copyright owners to reproduce any copyrighted material contained within this report. 


\section{Contents}

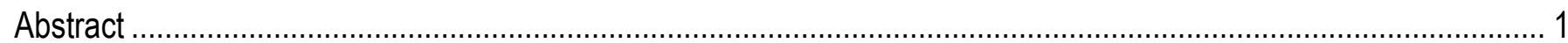

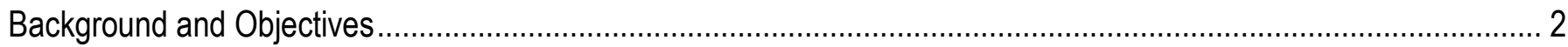

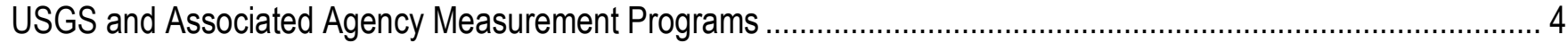

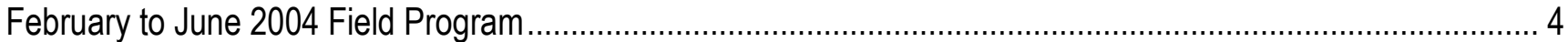

December 2007 to May 2008 Field Program....................................................................................... 5

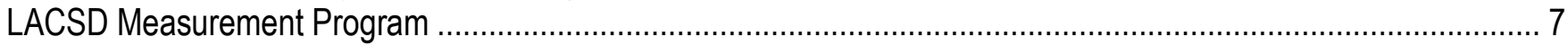

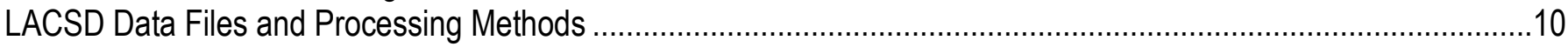

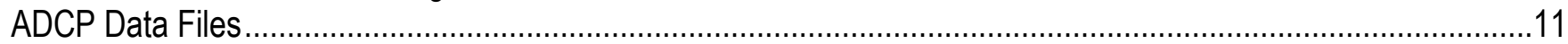

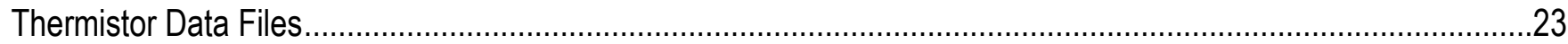

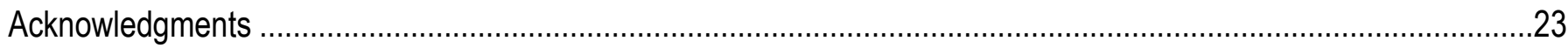

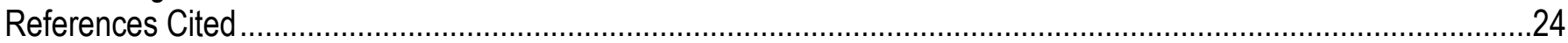

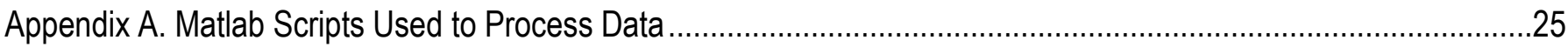

Appendix B. Temperature plots at Sites A1 through A9 and Sites AC, AE, and AG .............................................34

\section{Figures}

Figure 1. Map of the central southern California Bight and study area. Depth contours are in 100 meter intervals ...... 2

Figure 2. Locations of moorings deployed by LACSD, A, on the Palos Verdes Shelf and within San Pedro Bay ......... 3

Figure 3. Map of the Palos Verdes shelf region with the relevant LACSD (A sites) and USGS/SAIC (B sites) moorings with LACSD sites occupied during the array ............................................................................. 5

Figure 4. Timeline of current velocity data collected by USGS and LACSD in December 2007 to May 2008 ............... 6

Figure 5. Typical LACSD mooring setup with bottom tripod and thermistor string ……........................................ 7

Figure 6. Time series of the amplitude, signal-to-noise ratio (SNR), and the standard deviation of the correlation

(STDCOR) for currents measured just above the seabed (bins 1 and 2) at Site AH ............................................ 13

Figure 7. Time series of the amplitude, signal-to-noise ratio (SNR), and the standard deviation of the correlation (STDCOR) for currents measured just above the seabed (bin 1) and just below the sea surface

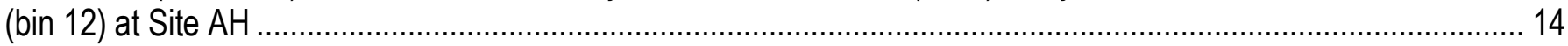

Figure 8. Timelines for the original current data the 21 LACSD sites (open circles denote short time periods when the data do not exist, usually because instruments were recovered and redeployed...................................... 15

Figure 9. Timelines for the current LACSD data set with small gaps filled during the USGS processing

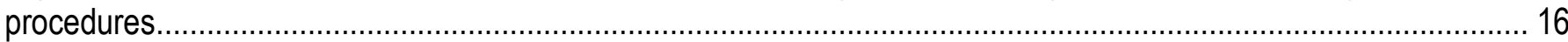

Figure 10. Time series of amplitude of the along-shelf (top panel) and cross-shelf (bottom panel) currents measured just above the seabed (bin 1), close to the seabed (bin 10), and just below the sea surface (bin 19) at

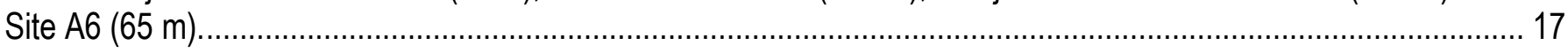

Figure 11. Vector plots of along- and cross-shelf subtidal currents measured just above the seabed (bin 1), close to the seabed (bin 10), and just below the sea-surface (bin 19) at Site A6 (65 m).....

Figure 12. Time series of amplitude of the along-shelf (top panel) and cross-shelf (bottom panel) currents measured just above the seabed (bin 1), close to the seabed (bin 5), and just below the sea-surface (bin 9) at Site A7 (35 m).

Figure 13. Vector plots of along- and cross-shelf subtidal currents measured just above the seabed (bin 1), close to the seabed (bin 5), and just below the sea surface (bin 9) at Site A7 (35 m) 


\section{Figures-Continued}

Figure 14. Time series of amplitude of the along-shelf (top panel) and cross-shelf (bottom panel) currents measured just above the seabed (bin 1), close to the seabed (bin 6), and just below the sea-surface (bin 11) at Site $\mathrm{AH}(20 \mathrm{~m})$

Figure 15. Vector plots of along- and cross-shelf subtidal currents measured just above the seabed (bin 1), close to the seabed (bin 6), and just below the sea-surface (bin 11) at Site AH (20 m)

\section{Tables}

Table 1. ADCP moorings deployed in the 2000-2008 LACSD ocean monitoring program......................................9

Table 2. Thermistor moorings deployed in the 2000-2008 LACSD ocean monitoring program............................... 10

Table 3. Mean and standard deviation of the amplitude, signal-to-noise ratio, and standard deviation of the correlation for currents at LACSD Site AH. 


\title{
Reformatted Data Sets Used in the Cooperative LACSD/USGS Palos Verdes Flow Study, 2000-2008
}

\author{
By Todd Anderson, Kurt Rosenberger, Anne L. Gartner
}

\begin{abstract}
Beginning in 1997, the Environmental Protection Agency (EPA) defined a contaminated section of the Palos Verdes shelf in southern California as a Superfund site, initiating a continuing investigation of this area. A number of agencies, including the EPA, U.S. Geological Survey (USGS), and Science Applications International Corporation (SAIC), conducted two oceanographic measurement programs in 2004 and 2007-2008 (SAIC, 2004, 2005; Rosenberger and others, 2010; Sherwood and others, unpublished data) to improve our understanding of the natural processes that resuspend and transport sediment in the area, especially in the region southeast of the Whites Point ocean outfall where earlier measurements were thought to be deficient.

Los Angeles County Sanitation Districts (LACSD) deployed a simpler but much broader array of instruments on the Palos Verdes shelf and within the northern reaches of San Pedro Bay from 2000 to 2008 in order to characterize the current and temperature patterns within these regions. This program overlapped the two programs run by USGS and other agencies in 2004 and 2007. The LACSD data were made available to the USGS and the EPA in order to support their joint efforts to model the transport of the contaminated sediments in the region.

This report describes the LACSD data sets, the instruments and data-processing procedures used, and the archive that contains the data sets that have passed our quality-assurance procedures.
\end{abstract}




\section{Background and Objectives}

The central portion of the Southern California Bight, from Point Dume in the north to Dana Point in the south, includes the continental shelves and slopes within Santa Monica and San Pedro Bays, off the Palos Verdes peninsula, and the many surrounding islands that lie offshore of the continental shelf (fig. 1). The Palos Verdes shelf itself is an 8-km-long, narrow strip of seabed between the two much larger bays. The shelf is a significant feature in the central Southern California Bight because much of the shelf is covered, where water depths are deeper than $30 \mathrm{~m}$, with a layer of sediment that is heavily contaminated with dichlorodiphenyltrichloroethane (DDT) and its daughter products. Because of these circumstances the region has been declared a Superfund site, under the supervision of the Environmental Protection Agency (EPA).

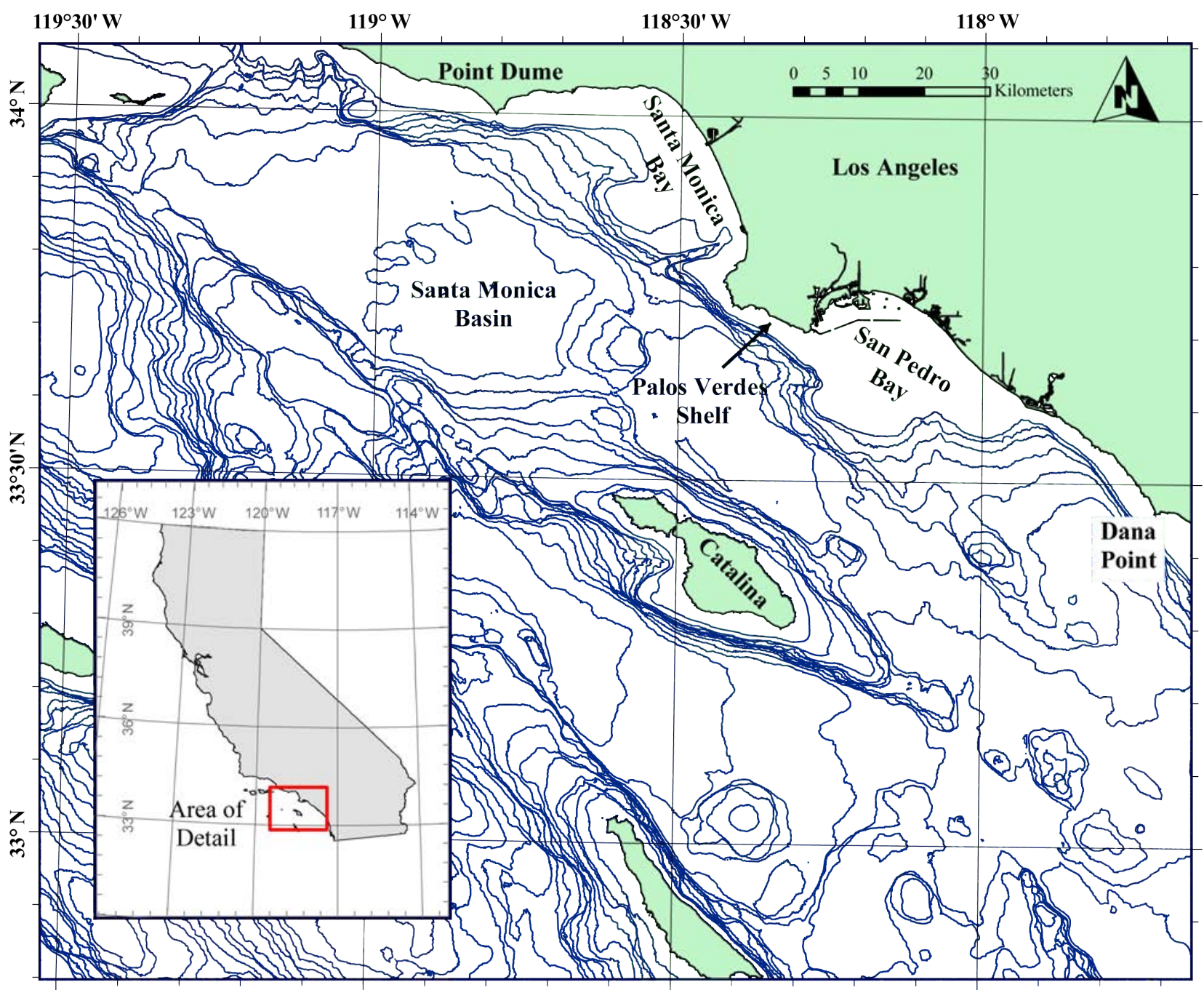

Figure 1. Map of the central southern California Bight and study area. Depth contours are in 100 meter intervals. 
In 1992-1993, the USGS and other agencies including the EPA, the U.S. Army Corps of Engineers (ACOE), and Science Applications International Corporation (SAIC) conducted a field study on the Palos Verdes shelf in order to determine the extent and eventual fate of the contaminants in the sediment deposit (Lee and Wiberg, 2002). In March to July of 2004 and December 2007 to May 2008, additional field programs measured oceanographic properties that could be used to refine predictions of the fate of these contaminated sediments (Science Applications International Corporation (SAIC) (2004, 2005, 2009); Noble and others, 2008; Rosenberger and others, 2010; Sherwood and others, unpublished data). Subsequently, the USGS and other agencies have collected or supported the collection of many more data sets, including data from several arrays of instruments deployed by Los Angeles County Sanitation Districts (LACSD) on the Palos Verdes shelf and within the northern reaches of San Pedro Bay from 2000 to 2008. Figure 2 shows the locations of the long-term LACSD moorings that began monitoring transport processes in the region in 2001. These data sets (LACSD, 2002; 2006; 2008) were used by the USGS and the EPA to monitor sediment and contaminant resuspension and transport processes, and to analyze the products to improve numerical models that predict the eventual fate of the sediments and contaminants. The proximity of many LACSD sites to USGS sites allows for useful comparison of data sets.

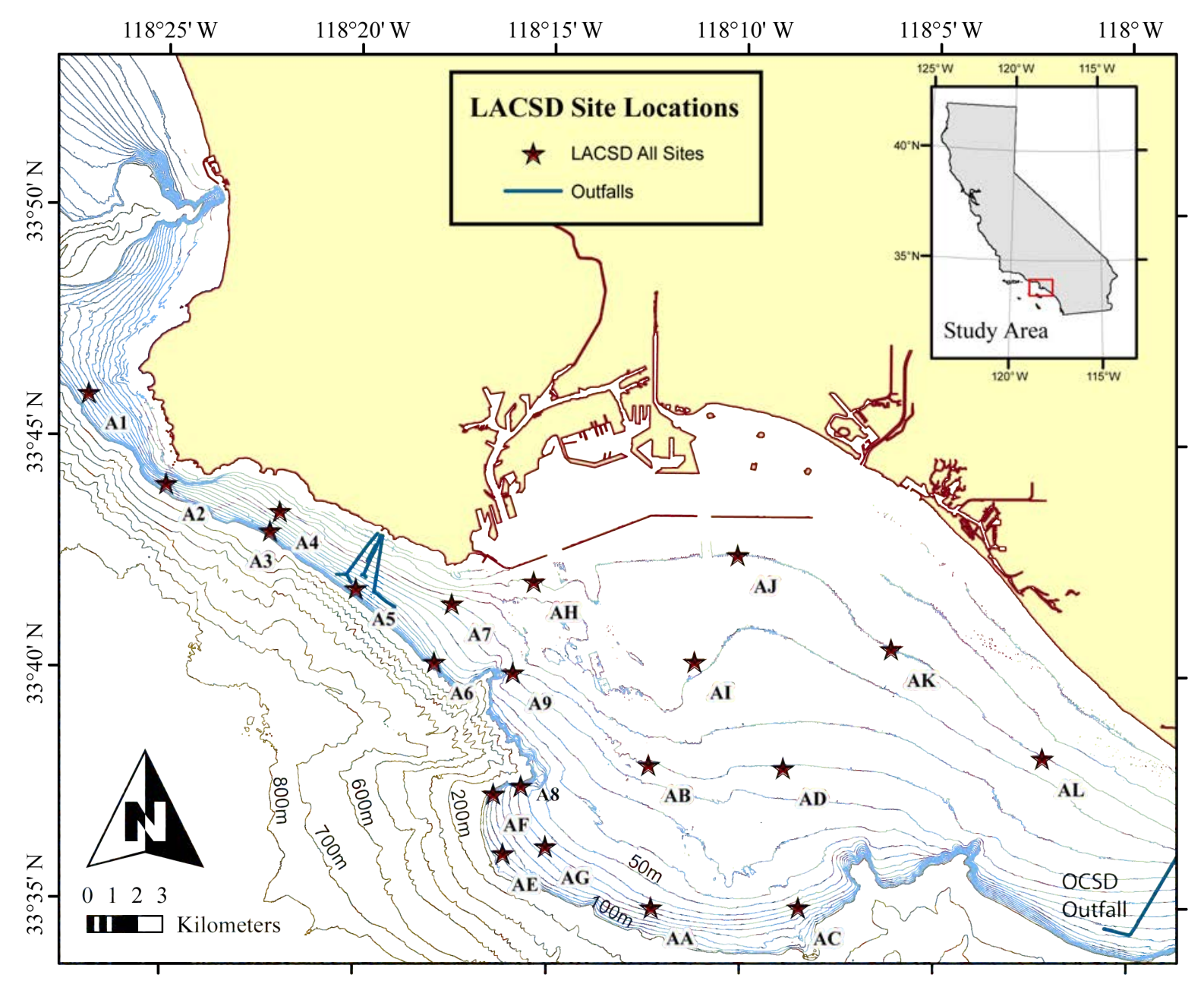

Figure 2. Locations of moorings deployed by LACSD, A, on the Palos Verdes Shelf and within San Pedro Bay. 


\section{USGS and Associated Agency Measurement Programs}

The primary purpose of the two recent oceanographic field programs that the USGS and associated agencies conducted on the Palos Verdes shelf was to obtain high-frequency data on the physical oceanographic processes that suspend sediments and their associated contaminants from the seabed and transport these materials along and across the shelf during the season when strong winter storms impact the region. These high-frequency data are needed to better characterize processes such as internal tides, internal bores, near-bottom currents associated with surface waves, and near-bed vertical stress profiles in order to help predict the ultimate fate of the contaminated sediment deposited on this shelf. The data sets are also used to support ongoing modeling and feasibility studies of contaminant transport and remediation programs for this region of the shelf.

The two field programs by the USGS and other agencies were conducted from February to June 2004 and December 2007 to May 2008. Full descriptions of each field program are given in SAIC (2005), Rosenberger and others (2010), and Sherwood and others (unpublished data). A summary of each program is presented here for context. Data from many of the instruments deployed in the LACSD field program supplemented the measurements collected in both of these short field programs.

\section{February to June 2004 Field Program}

The USGS and its associated agencies deployed sets of moorings at 6 sites on the Palos Verdes shelf during the winter of 2004 (fig. 3). Three of the sites (B2, B3, and B6) were located on the 60-m isobath, with the center station (Site B3) located not only near the thickest region of the contaminated sediment deposit, but near a historic measurement site occupied in 1992. The other three sites (BX, B6.5, B7), together with Site B6, were set along a line across the southeastern part of the shelf to monitor processes that occurred near to and upcoast of the head of the deposit. These sets of measurements were designed to assess the potential for currents to erode the sediments in this region of the shelf. Hence, the set of instruments deployed at these sites not only monitored the vertical profile of currents and temperature, similar to the properties monitored by instruments in the LACSD array, but also monitored the much higher frequency resuspension processes that are concentrated near the seabed. 


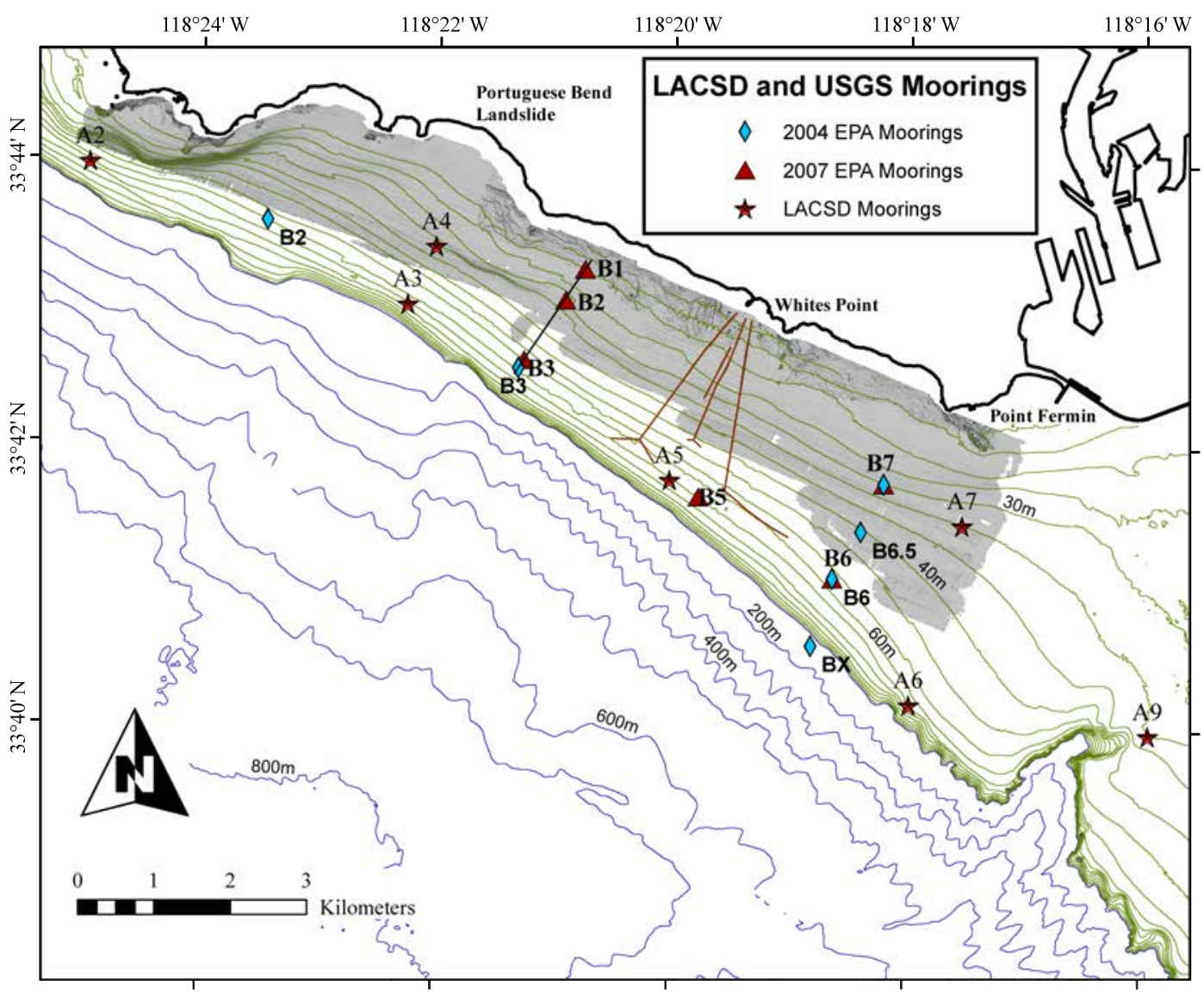

Figure 3. Map of the Palos Verdes shelf region with the relevant LACSD (A sites) and USGS/SAIC (B sites) moorings with LACSD sites occupied during the array. Ocean outfall pipelines are shown as black. Depth contours in green are at 15 meter intervals, and depth contours in blue are at 100 meter intervals.

\section{December 2007 to May 2008 Field Program}

The USGS deployed sets of moorings at six sites on the Palos Verdes shelf during the winter of 2008 (fig. 3). Three of the sites (Sites B3, B5, and B6) were located on the 60-m isobath, with the center site, B5, sited between the outer arms of the ocean outfall pipes. Sites B3 and B6 were near their counterparts deployed in the 2004 field program. The other moorings were deployed along two crossshelf arrays anchored at the outer edge near Sites B3 and B6. This set of instruments monitored not only sediment resuspension and transport processes, but at two sites (B3 and B6), instruments measured the complete current profile from a few meters below the sea surface to the seafloor. At the inshore USGS site, B1, instruments monitored transport patterns at a site much closer to the shore than found in previous field programs. Note that USGS Site B5 is adjacent to LACSD Site A5, which allowed for easy comparison of data sets collected by the USGS- and LACSD-led programs. 
The timelines for the deployment programs in the winter of 2007-2008 are plotted in figure 4.

Palos Verdes/LACSD Current Velocity Data

Instruments deployed

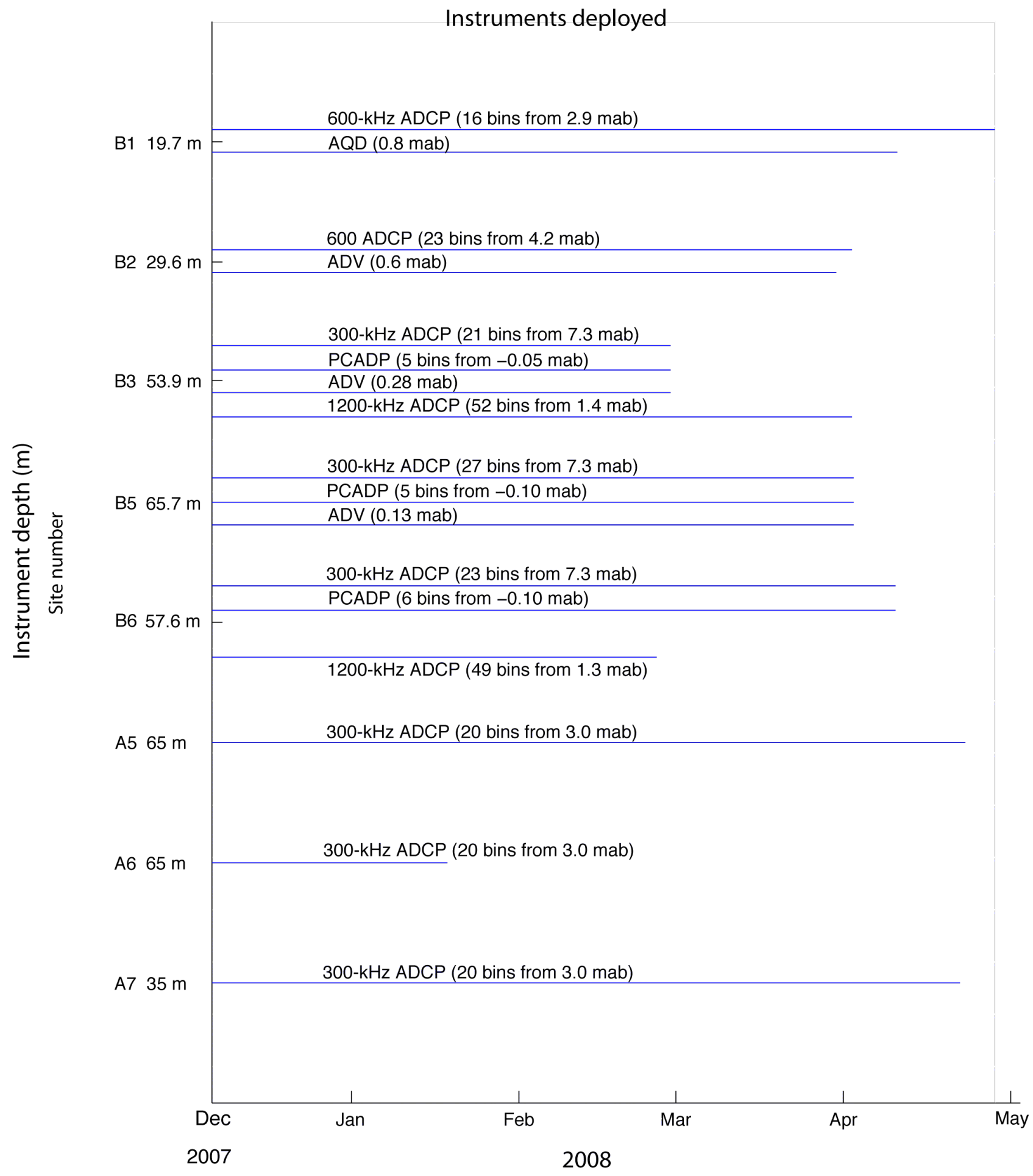

Figure 4. Timeline of current velocity data collected by USGS and LACSD in December 2007 to May 2008. 


\section{LACSD Measurement Program}

At each of the current meter moorings, a SonTek, Inc., Acoustic Doppler Current Profiler (ADCP) was deployed in an up-looking configuration (fig. 5), protected within a trawl-resistant bottom mount (TRBM). The 500-kHz, 4-head ADCP meters were equipped with 30 megabytes of internal data storage capacity and were powered from an external battery canister containing three 36 " $\mathrm{D}$ " cell alkaline battery packs. With this storage and power capability the ADCPs were conservatively configured to sample data into three-meter vertical depth bins from around $3 \mathrm{~m}$ above the bed (mab) to within a few meters of the surface every 15 minutes for a period of three months. During each 15minute sampling period, the meter actively "pinged" the water column for three minutes. In June 2007, five ADCPs (Sites AH-AL) were redeployed on the central and inner part of the San Pedro shelf. At these five mooring the ADCPs were configured to record data into 1.5-m vertical bins. In order to keep the error as close as possible to $1 \mathrm{~cm} / \mathrm{s}$, these meters were configured to actively ping for 5 minutes each 15 minutes.

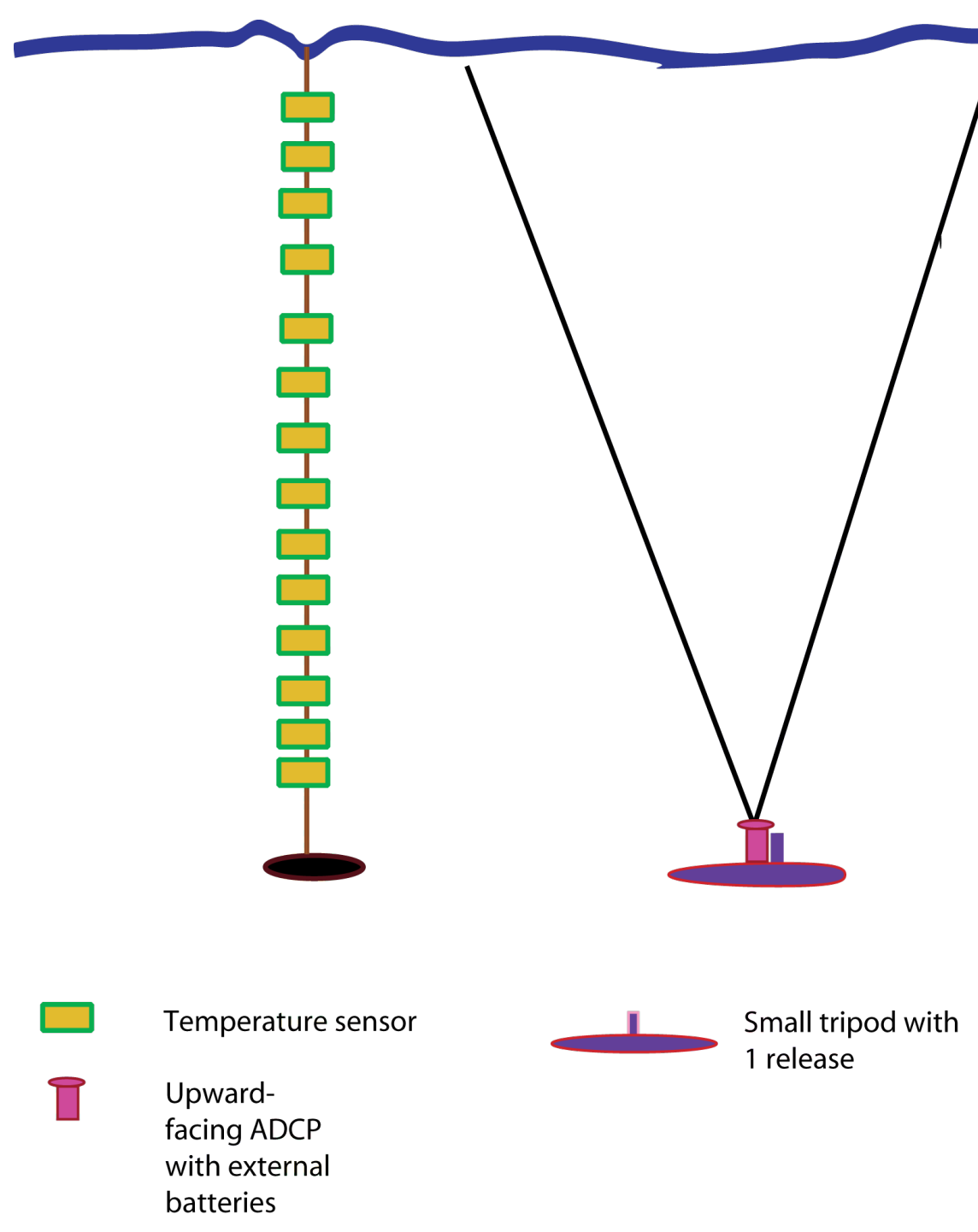

Figure 5. Typical LACSD mooring setup with bottom tripod and thermistor string. 
The Aquatec, Ltd., thermistor logger mooring strings were deployed next to the ADCP moorings. Thermistors were located every $3 \mathrm{~m}$ along the mooring from a depth of $2 \mathrm{~m}$ below the surface to the seabed and were set to $\log$ temperature data every 15 minutes. The depth of each thermistor was centered on the adjacent ADCP current bin. Figure 5 shows a typical LACSD mooring setup.

The array was first deployed in 2000; it consisted of nine bottom-mounted ADCP and 9 thermistor string moorings. In 2002, the Palos Verdes Flow Study area was expanded by adding four additional sites (AA, AB, AC, AD) on the San Pedro shelf. All four of these added sites (AA-AD) had a bottom mounted ADCP (fig. 2). Only one site, AC, deployed next to the current meter at Site AC, had a thermistor string mooring. Between 2002 and 2009 a number of additional adjustments were made to the sampling locations. In August 2004, the thermistor string (T4) from Site A4 (adjacent to Site A4) was moved and redeployed with a new ADCP at a new site, AE/TE in $89 \mathrm{~m}$ water depth on the outer San Pedro shelf (fig. 2). In January 2006, the current meter and thermistor string from Site A8/T8 were moved and redeployed at a new site, AG/TG, which was still in $65 \mathrm{~m}$ of water but located approximately $2.5 \mathrm{~km}$ farther southwest on the outer San Pedro shelf (fig. 2). In February 2006, the current meter at Site A4 was redeployed to a new site, AF, located in $89 \mathrm{~m}$ water depth on the outer San Pedro shelf (fig.2). The positions and dates of deployment for the ADCP and thermistor moorings are listed in tables 1 and 2, respectively. In October 2006, the thermistor mooring site T2 was permanently removed, and in January 2007, the thermistor mooring site T3 was also permanently removed. In May 2007, ADCP mooring sites A1, A2, A3, A9, and AF were permanently removed from their original locations and redeployed at sites on the inner San Pedro shelf and reidentified as Sites AH, AI, AJ, AK, and AL. Also during May 2007, thermistor mooring sites T1, T9, and TGR were permanently removed (Site TG was rigged with additional subsurface floatation and was left in place). Site T7 was removed in May 2007 but was redeployed in September 2007. In January 2008, ADCP Sites A6, AE, AG, AH and AI, and thermistor string mooring sites T6, TE, and TG were permanently removed. In April of 2008, all remaining $\mathrm{ADCP}$ mooring sites $\mathrm{A} 5, \mathrm{~A} 7, \mathrm{AA}, \mathrm{AB}, \mathrm{AC}$, and $\mathrm{AD}$, and thermistor mooring sites $\mathrm{T} 5, \mathrm{~T} 7$, and TC were permanently removed, ending the field portion of the study.

Due to a problem with circuitry on the battery packs used for the ADCP meters, most of the ADCPs failed to record any data during the fall of 2003. 
Table 1. ADCP moorings deployed in the 2000-2008 LACSD ocean monitoring program.

[Note that many of the ADCP moorings are deployed with a common thermistor mooring. Hence ADCP Site A1 is located next to thermistor Site T1, Site A2 next to Site T2, and so on. Each ADCP monitors the vertical profile of currents from X m above bottom (mab) to within Y m below the surface in 3-m bins every 15 minutes. The center of an ADP bin is designed to correspond to a temperature measurement on the companion thermistor mooring. The start date denotes the earliest time an instrument was deployed. The stop time denotes the last time it was recovered. Note there can be significant gaps in the actual data sets]

\begin{tabular}{|c|c|c|c|c|c|}
\hline Site & Latitude & Longitude & Depth & Data Start Date & Data End Date \\
\hline A1 & $33^{\circ} 45^{\prime} 55^{\prime \prime}$ & $-118^{\circ} 27^{\prime} 00^{\prime \prime}$ & 65 & 20 Nov 2000 & 21 May 2007 \\
\hline A2 & $33^{\circ} 44^{\prime} 58^{\prime \prime}$ & $-118^{\circ} 25.58^{\prime \prime}$ & 65 & 03 Nov 2000 & 21 May 2007 \\
\hline A3 & $33^{\circ} 43.59^{\prime \prime}$ & $-118^{\circ} 22^{\prime} 15^{\prime \prime}$ & 65 & 20 Nov 2000 & 06 Jun 2007 \\
\hline A4 & $33^{\circ} 43^{\prime} 24^{\prime \prime}$ & $-118^{\circ} 22^{\prime} 12^{\prime \prime}$ & 35 & 28 Nov 2000 & 14 Feb 2006 \\
\hline A5 & $33^{\circ} 42^{\prime} 46^{\prime \prime}$ & $-118^{\circ} 20^{\prime} 13^{\prime \prime}$ & 65 & 02 Nov 2000 & 23 Apr 2008 \\
\hline A6 & $33^{\circ} 40^{\prime} 11^{\prime \prime}$ & $-118^{\circ} 18^{\prime} 58^{\prime \prime}$ & 65 & 28 Nov 2000 & $18 \operatorname{Jan} 2008$ \\
\hline A7 & $33^{\circ} 41^{\prime} 28^{\prime \prime}$ & $-118^{\circ} 18^{\prime} 32^{\prime \prime}$ & 35 & 20 Nov 2000 & 22 Apr 2008 \\
\hline A8 & $33^{\circ} 38^{\prime} 32^{\prime \prime}$ & $-118^{\circ} 16^{\prime} 41^{\prime \prime}$ & 65 & 03 Nov 2000 & 26 Jan 2008 \\
\hline A9 & $33^{\circ} 40^{\prime} 59^{\prime \prime}$ & $-118^{\circ} 16^{\prime} 56^{\prime \prime}$ & 35 & 04 Dec 2000 & 06 Jun 2007 \\
\hline AA & $33^{\circ} 35^{\prime} 56^{\prime \prime}$ & $-118^{\circ} 12^{\prime} 17^{\prime \prime}$ & 65 & $25 \mathrm{Feb} 2002$ & 21 Apr 2008 \\
\hline $\mathrm{AB}$ & $33^{\circ} 38^{\prime} 13^{\prime \prime}$ & $-118^{\circ} 12^{\prime} 24^{\prime \prime}$ & 35 & 08 Aug 2002 & 21 Apr 2008 \\
\hline $\mathrm{AC}$ & $33^{\circ} 35^{\prime} 58^{\prime \prime}$ & $-118^{\circ} 85^{\prime} 29^{\prime \prime}$ & 65 & 29 Aug 2002 & 21 Apr 2008 \\
\hline $\mathrm{AD}$ & $33^{\circ} 38^{\prime} 59^{\prime \prime}$ & $-118^{\circ} 89^{\prime} 55^{\prime \prime}$ & 35 & 01 Sep 2007 & 24 Apr 2008 \\
\hline $\mathrm{AE}$ & $33^{\circ} 36^{\prime} 36^{\prime \prime}$ & 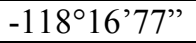 & 89 & 03 Aug 2004 & 18 Jan 2008 \\
\hline $\mathrm{AF}$ & $33^{\circ} 37^{\prime} 21^{\prime \prime}$ & $-118^{\circ} 16^{\prime} 24^{\prime \prime}$ & 89 & 14 Feb 2006 & 06 Jun 2007 \\
\hline AG & $33^{\circ} 36^{\prime} 13^{\prime \prime}$ & $-118^{\circ} 15^{\prime} 25^{\prime \prime}$ & 65 & 26 Jan 2006 & 18 Jan 2008 \\
\hline $\mathrm{AH}$ & $33^{\circ} 42^{\prime} 57^{\prime \prime}$ & $-118^{\circ} 15^{\prime} 24^{\prime \prime}$ & 20 & 06 Jun 2007 & 15 Jan 2008 \\
\hline $\mathrm{AI}$ & $33^{\circ} 40^{\prime} 16^{\prime \prime}$ & $-118^{\circ} 11^{\prime} 14^{\prime \prime}$ & 23 & 06 Jun 2007 & 16 Jan 2008 \\
\hline $\mathrm{AJ}$ & $33^{\circ} 43^{\prime} 34^{\prime \prime}$ & $-118^{\circ} 10^{\prime} 77^{\prime \prime}$ & 20 & 06 Jun 2007 & 16 Jan 2008 \\
\hline AK & $33^{\circ} 41^{\prime} 34^{\prime \prime}$ & $-118^{\circ} 61^{\prime} 83^{\prime \prime}$ & 20 & 04 Jun 2007 & $16 \operatorname{Jan} 2008$ \\
\hline $\mathrm{AL}$ & $33^{\circ} 38^{\prime} 14^{\prime \prime}$ & $-118^{\circ} 22^{\prime} 48^{\prime \prime}$ & 20 & 04 Jun 2007 & 16 Jan 2008 \\
\hline
\end{tabular}


Table 2. Thermistor moorings deployed in the 2000-2008 LACSD ocean monitoring program.

[Note that thermistor mooring sites are paired with ADCP mooring sites. Hence, thermistor Site T1 is located next to ADCP Site A1, Site T2 next to Site A2, and so on. The thermistors are spaced every $3 \mathrm{~m}$ on each mooring and measure the water temperature every 15 minutes. The planned depths of the thermistors are centered in the middle of the companion bin of the adjacent ADCP. The start date denotes the earliest time the mooring was deployed. The stop time denotes the last time it was recovered. Note there can be significant gaps in the actual data sets from individual thermistors]

\begin{tabular}{|c|c|c|c|c|c|}
\hline Site & Latitude & Longitude & Depth & Data Start Date & Data End Date \\
\hline$\overline{\mathrm{T} 1}$ & $33^{\circ} 45^{\prime} 55^{\prime \prime}$ & $-118^{\circ} 27^{\prime} 00^{\prime \prime}$ & 2 to 65 & 20 Nov 2000 & 21 May 2007 \\
\hline $\mathrm{T} 2$ & $33^{\circ} 44^{\prime} 58^{\prime \prime}$ & $-118^{\circ} 25.58^{\prime \prime}$ & 2 to 65 & 03 Nov 2000 & 24 Oct 2006 \\
\hline T3 & $33^{\circ} 43.59^{\prime \prime}$ & $-118^{\circ} 22^{\prime} 15^{\prime \prime}$ & 2 to 65 & 20 Nov 2000 & 22 Jun 2007 \\
\hline $\mathrm{T} 4$ & $33^{\circ} 43^{\prime} 24^{\prime \prime}$ & $-118^{\circ} 22^{\prime} 12^{\prime \prime}$ & 2 to 35 & 28 Nov 2000 & 03 Aug 2004 \\
\hline $\mathrm{T} 5$ & $33^{\circ} 42^{\prime} 46^{\prime \prime}$ & $-118^{\circ} 20^{\prime} 13^{\prime \prime}$ & 2 to 65 & 01 Nov 2000 & 23 Apr 2008 \\
\hline T6 & $33^{\circ} 40^{\prime} 11^{\prime \prime}$ & $-118^{\circ} 18^{\prime} 58^{\prime \prime}$ & 2 to 65 & 28 Nov 2000 & 14 Jan 2008 \\
\hline $\mathrm{T} 7$ & $33^{\circ} 41^{\prime} 28^{\prime \prime}$ & $-118^{\circ} 18^{\prime} 32^{\prime \prime}$ & 2 to 35 & 21 Nov 2000 & 21 Apr 2008 \\
\hline $\mathrm{T} 8$ & $33^{\circ} 38^{\prime} 32^{\prime \prime}$ & $-118^{\circ} 16^{\prime} 41^{\prime \prime}$ & 2 to 65 & 01 Nov 2000 & $26 \operatorname{Jan} 2006$ \\
\hline T9 & $33^{\circ} 40^{\prime} 59^{\prime \prime}$ & $-118^{\circ} 16^{\prime} 56^{\prime \prime}$ & 2 to 35 & 04 Dec 2000 & 22 May 2007 \\
\hline $\mathrm{TC}$ & $33^{\circ} 35^{\prime} 58^{\prime \prime}$ & $-118^{\circ} 85^{\prime} 29^{\prime \prime}$ & 2 to 65 & 29 Aug 2002 & 21 Apr 2008 \\
\hline TE & $33^{\circ} 36^{\prime} 36^{\prime \prime}$ & $-118^{\circ} 16^{\prime} 77^{\prime \prime}$ & 8 to 89 & 03 Aug 2004 & $18 \operatorname{Jan} 2008$ \\
\hline TG & $33^{\circ} 36^{\prime} 13^{\prime \prime}$ & $-118^{\circ} 15^{\prime} 25^{\prime \prime}$ & 2 to 65 & 26 Jan 2006 & 18 Jan 2008 \\
\hline
\end{tabular}

\section{LACSD Data Files and Processing Methods}

All LACSD data sets received by the USGS were initially edited and reviewed for quality by LACSD (Steele, 2009), then sent to the USGS. Each ADCP outputs Sontek proprietary binary files when the ADCP current bins are recovered; the raw data files were examined in the SonTek VIEWADP software, where the current components, signal amplitude and other information were reviewed. To build final processed data files, the VIEWADP "Data Export", "All" function was used to produce approximately 20 separate output ASCII files from each ADCP file. No rotation correction was applied to the current components either within the ADCP, or during the ASCII output from the Sontek software (however, a magnetic to true north correction was applied to final files).

The data was given to the USGS as ASCII .csv (Comma Separated Variable) files, with a single .csv format file for each mooring site, containing all data for that mooring since the beginning of the study. The USGS reviewed the data files for quality, trimmed the beginning and end of each file to remove times when the sites no longer had data, corrected the timestamp from Pacific Standard Time (PST) to Greenwich Mean Time (GMT), and then converted the files to USGS netCDF format (Xu and others, 2002). The netCDF files contain self-describing metadata such as start/stop dates, measurement depths, and water depth. A full description of the netCDF format is given in Montgomery and others (2008).

Appendix A shows the Matlab scripts used to process the data. 


\section{ADCP Data Files}

The files include all useful current-velocity data collected at the individual sites for the entire LACSD field program (table 1). Each file contains current velocities for each bin and ancillary data relevant to the individual data sets, such as the depth of the center of each current bin. Since the time base was not explicitly included in the LACSD data file, a time base with a 15-minute sampling interval was created when the data files were converted to the netCDF format.

The ADCPs monitored the east/west and north/south components of current velocity from approximately 3 meters above bed (mab) to within 1-5 m below the Mean Lower Low water (MLLW) level. All measurement bins were $3 \mathrm{~m}$ wide, except for data from instruments deployed at the nearshore Sites AH-AL where bins were $1.5 \mathrm{~m}$ wide. Current velocities were recorded every 15 minutes for three minutes. The result of this active sampling was averaged and recorded to represent the corresponding 15-minute time period. This sampling protocol was selected to assure that under normal conditions the error of the measured current speed in all bins would be less than $1 \mathrm{~cm} / \mathrm{sec}$. At Sites AH-AL, the active pinging lasted 5 out of 15 minutes. This setup resulted in an instrument precision of better than $1 \mathrm{~cm} / \mathrm{sec}$ for each current measurement.

The current bins are sequentially numbered from the bin closest to the seabed to the bin nearest the surface. Hence, bin 1 is nearest the seabed at all sites. Note that currents in the very-near-surface bins (that is, within $5 \mathrm{~m}$ of MLLW) may contain instrument errors because the velocities measured are located nearer to the surface than the manufacturer recommends (that is, within 10 percent of the watercolumn height, a number that changes with tidal stage). A judgment on the quality of the data in the near-surface bins is left to the discretion of the user.

The resultant netCDF current data sets were checked for obvious translation errors, then assigned a USGS filename. For each station, the netCDF file contains at least the following:

- Time of each measurement (GMT)

- Center depth of each bin

- East (cross-shore) current velocity in each bin

- North (alongshore) current velocity in each bin

- Signal amplitude of each bin

- Signal-to-noise ratio (SNR) of each bin

- Standard deviation of correlation (STDCOR) of each bin

The signal amplitude is the averaged amplitude of the returned signal with time.

The SNR is the amplitude of the returned signal over the ambient background noise with time.

The STDCOR is the average standard deviation of each bin divided by the correlation of currents in the water column with time. 
The last three data variables allow one to estimate the quality of the current data stored in each bin of the netCDF file. A "good" current measurement has (1) relatively high signal amplitude, (2) a relatively high SNR, and (3) a relatively small STDCOR. The standard deviation of these three variables should be relatively small. Hence, comparing these quantities for currents measured near the seabed and currents measured near the sea surface then:

The signal amplitude decreases with distance from the seabed (increasing bin number).

The SNR amplitude tends to decrease with distance from the seabed.

The STDCOR amplitude tends to increase with distance from the seabed.

The standard deviation of all three quantities tends to increase with distance from the seabed.

As an example, these quantities were compared for currents measured nearest the seabed (bin 1), close to the seabed (bin 2), and nearest the water surface (bin 12) at Site AH (figs. 6 and 7; table 3). The data suggest that the near-surface current properties may be suspect; the near-surface bins have much larger variance for all quantities when compared to those measured at the two bins near the seabed.

Table 3. Mean and standard deviation of the amplitude, signal-to-noise ratio, and standard deviation of the correlation for currents at LACSD Site $\mathrm{AH}$.

\begin{tabular}{|c|c|c|c|c|c|c|}
\hline \multirow{2}{*}{$\begin{array}{c}\text { Bin/ } \\
\text { Burst\# }\end{array}$} & \multicolumn{2}{|c|}{ Amplitude } & \multicolumn{2}{c|}{ Signal to Ratio } & \multicolumn{2}{c|}{ Standard Correlation } \\
\cline { 2 - 5 } & Mean & $\begin{array}{c}\text { Standard } \\
\text { Deviation }\end{array}$ & Mean & $\begin{array}{c}\text { Standard } \\
\text { Deviation }\end{array}$ & Mean & $\begin{array}{c}\text { Standard } \\
\text { Deviation }\end{array}$ \\
\hline
\end{tabular}

\begin{tabular}{|l|c|c|c|c|c|c|}
\hline 1 & 137.5444 & & 49.9647 & 3.7158 & 0.8645 & 0.0506 \\
\hline 2 & 130.1905 & & 46.8013 & 3.7227 & 0.8320 & 0.0510 \\
\hline 3 & 123.0466 & 8.7542 & 43.7300 & 3.7501 & 0.8185 & 0.0503 \\
\hline 4 & 117.4691 & 8.6857 & 41.3305 & 3.7178 & 0.8179 & 0.0483 \\
\hline 5 & 112.7950 & 8.6032 & 39.3185 & 3.6814 & 0.8234 & 0.0466 \\
\hline 6 & 108.7209 & 8.6746 & 37.5648 & 3.7114 & 0.8312 & 0.0458 \\
\hline 7 & 105.0323 & 8.8803 & 35.9798 & 3.7971 & 0.8405 & 0.0464 \\
\hline 8 & 101.5392 & 9.1417 & 34.4791 & 3.9080 & 0.8517 & 0.0478 \\
\hline 9 & 98.3053 & 9.4160 & 33.0892 & 4.0233 & 0.8650 & 0.0525 \\
\hline 10 & 95.7702 & 9.7731 & 32.0003 & 4.1722 & 0.8877 & 0.0629 \\
\hline 11 & 97.9570 & 10.8801 & 32.9413 & 4.6410 & 0.9335 & 0.0860 \\
\hline 12 & 107.0725 & 17.1418 & 36.8615 & 7.3338 & 1.0261 & 0.1504 \\
\hline
\end{tabular}


Site AH

\section{Amplitude}
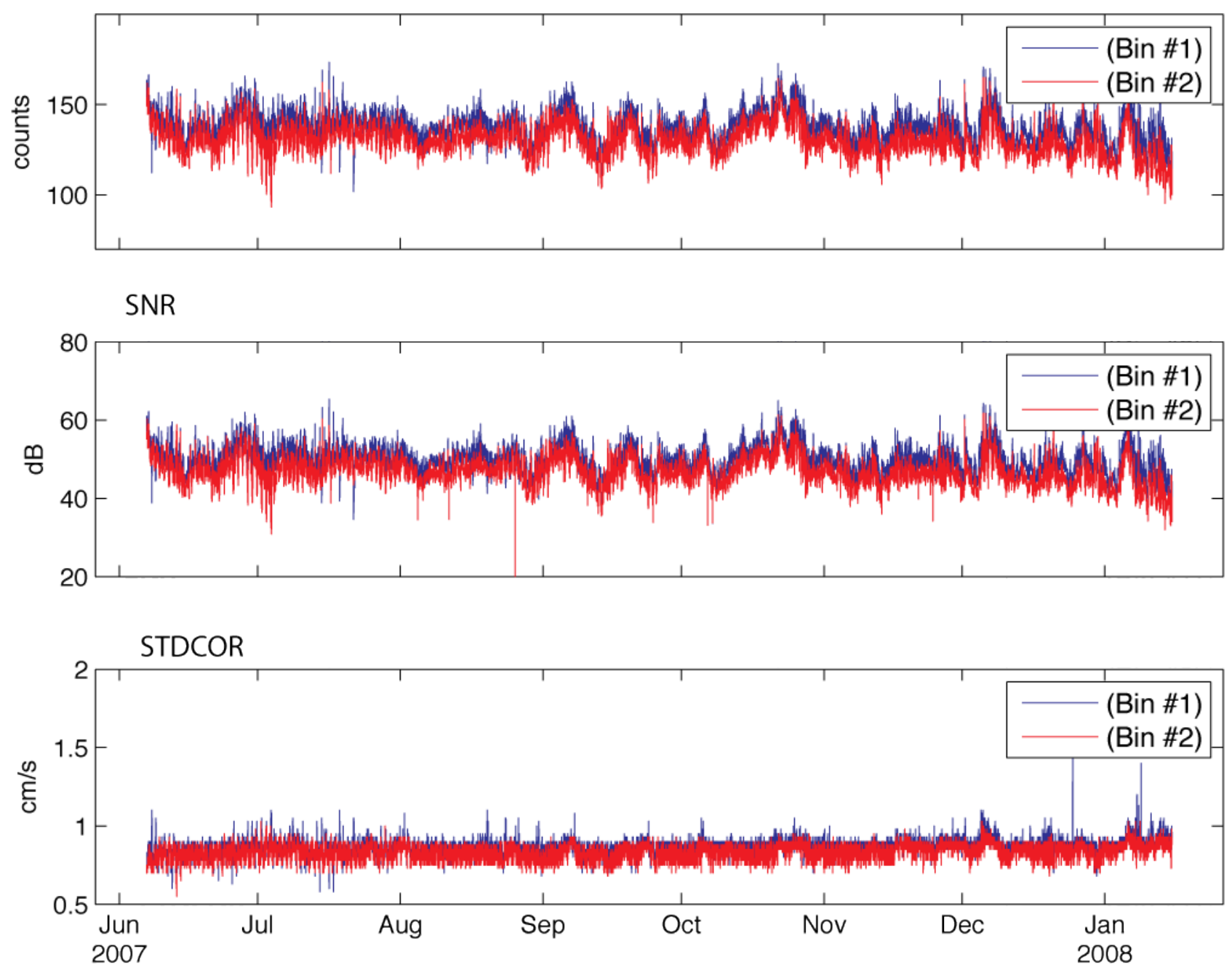

Figure 6. Time series of the amplitude, signal-to-noise ratio (SNR), and the standard deviation of the correlation (STDCOR) for currents measured just above the seabed (bins 1 and 2) at Site $\mathrm{AH}$. 
Site $\mathrm{AH}$
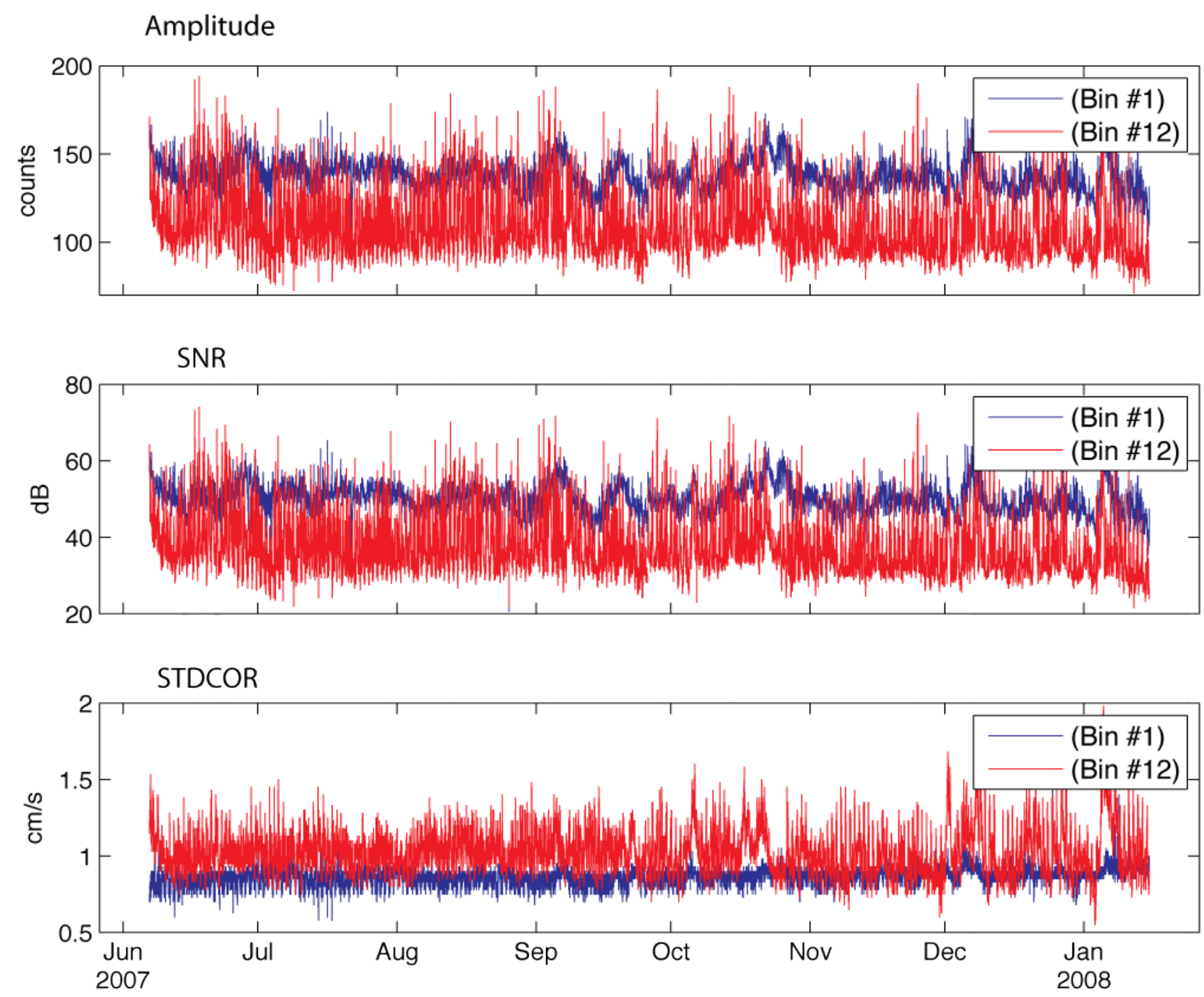

Figure 7. Time series of the amplitude, signal-to-noise ratio (SNR), and the standard deviation of the correlation (STDCOR) for currents measured just above the seabed (bin 1) and just below the sea surface (bin 12) at Site AH. 
The times when good data exist in the original files from LACSD is depicted in figure 8. Note that these data records have many small temporal gaps caused by deployment and recovery operations. The longer gaps found in most records in 2004 were caused by instrument malfunctions. There are additional small gaps in some data records that are not depicted in this figure.

In a subsequent processing step, short gaps in the original data sets were bridged (fig. 9). Gaps of less than 4 points ( 1 hour) were filled using a linear interpolation scheme. Gaps up to 48 points (12 hours) were filled with a data set created using the spectral characteristics of the data on both sides of the gap (Anderson, 1974). Larger temporal gaps were not filled. Bridged points in the NetCDF files are flagged with a value of 1 ; non-bridged points have a flag value of 0 . Note that most of the temporal gaps caused by deployment/recovery operations have been filled in the bridged files. Hence, the bridged current records are much more continuous. The large temporal gap in 2004 is still present in most current records. The filename for an original ADCP record is "LA00station_name.nc". For a bridged file, the filename is "LA00station_namebr.nc". Hence, the bridged filename at Site A7 is LA00A7br.nc.

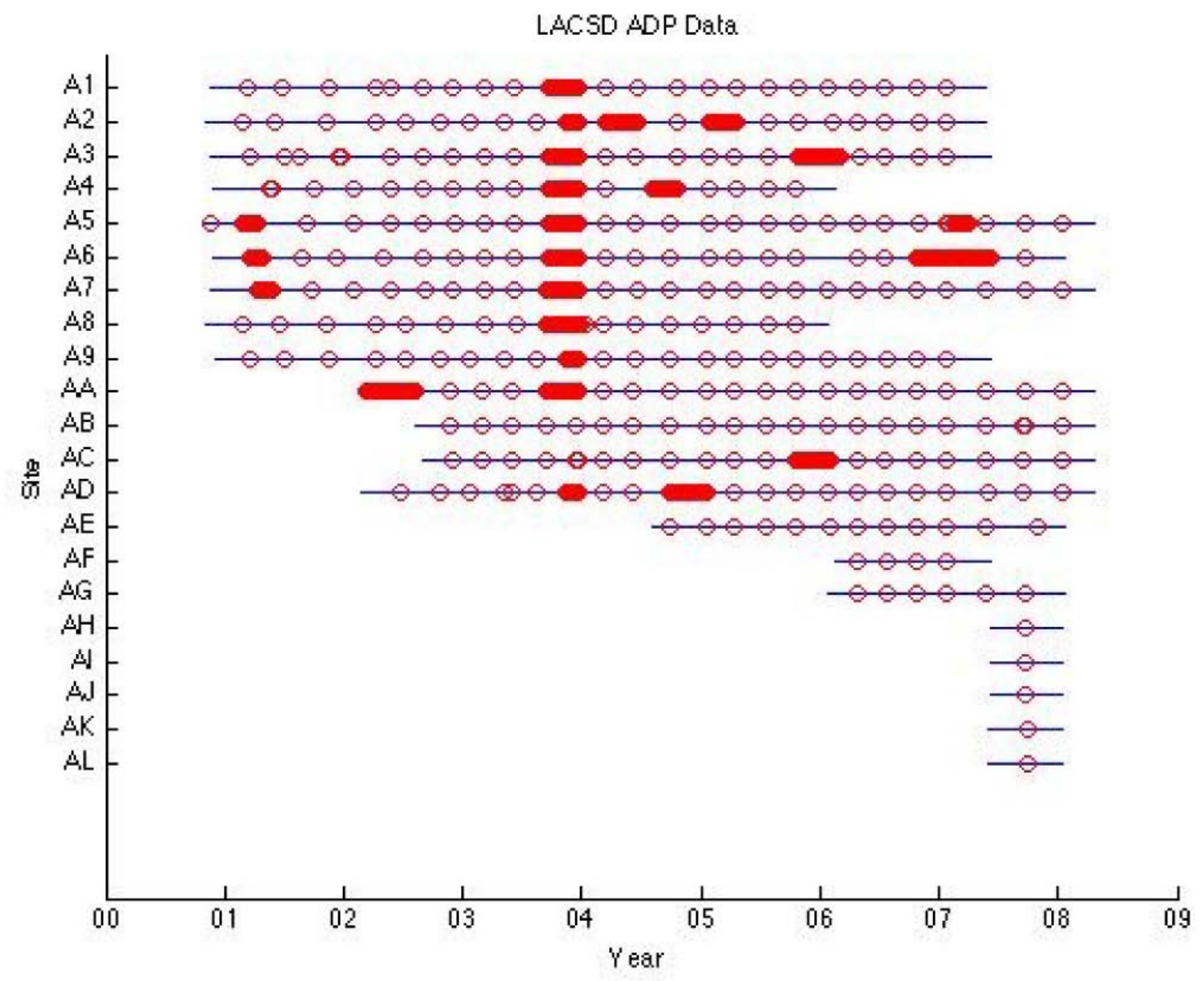

Figure 8. Timelines for the original current data the 21 LACSD sites (open circles denote short time periods when the data do not exist, usually because instruments were recovered and redeployed. The filled red ovals represent longer temporal gaps in individual records). 


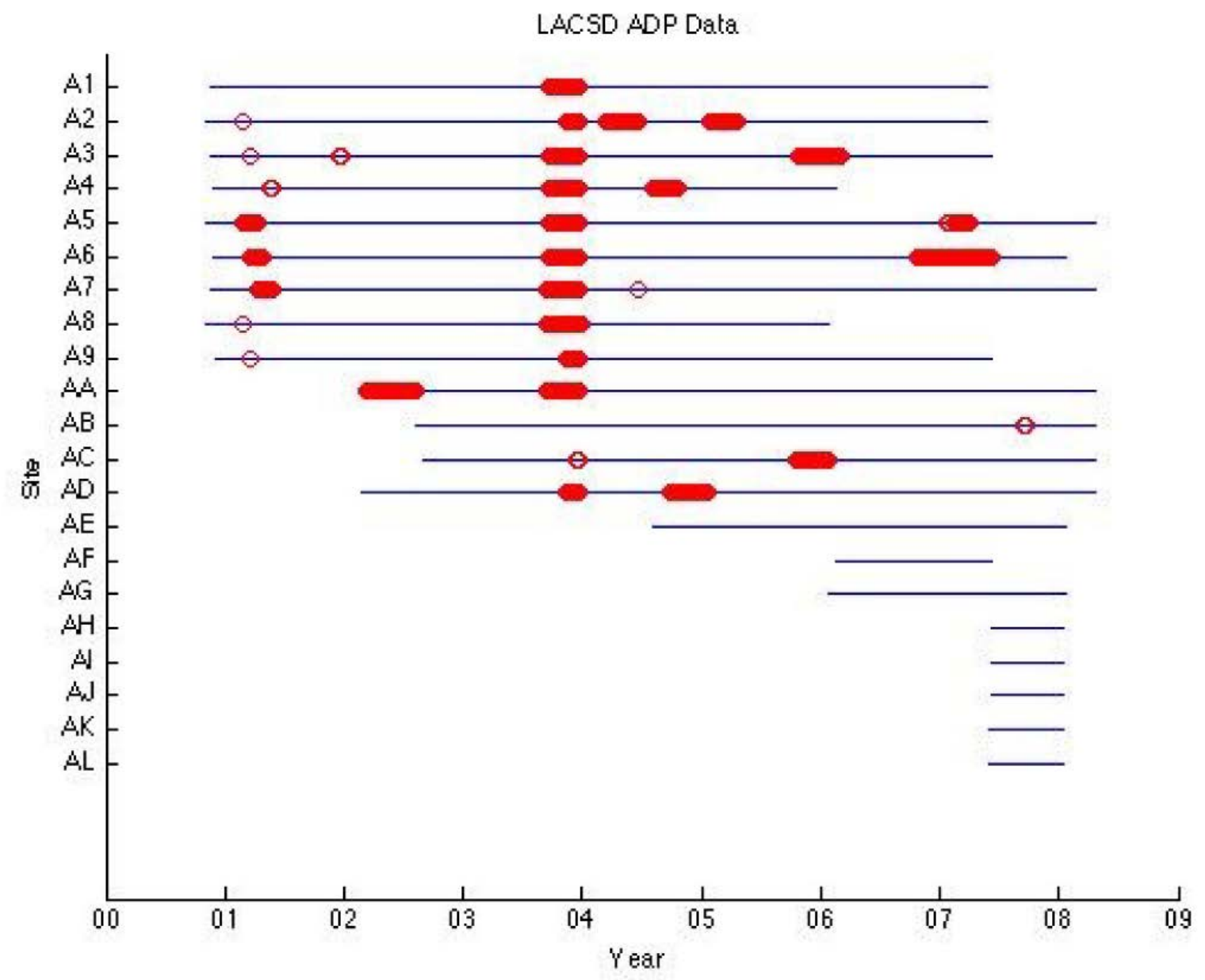

Figure 9. Timelines for the current LACSD data set with small gaps filled during the USGS processing procedures. The small temporal gaps that still exist in individual records are denoted by small open circles. Filled ovals denote the larger gaps.

For convenience, a third data set was created from selected bridged current records. This more continuous data set has been clipped to cover the time that the USGS moorings were deployed (March to July 2004 and Dec 2007 to April 2008). The naming convention for these data sets is "LA00station_namesubsetbrTIME.nc". Hence, the first short data set at Site A5 is LA00A5subsetbr2004.nc.

Figures 10 to 15 depict the characteristics of the hourly and subtidal (that is, currents with periods shorter than 33 hours removed from the record) current fields at selected sites. 


\section{Site A6}
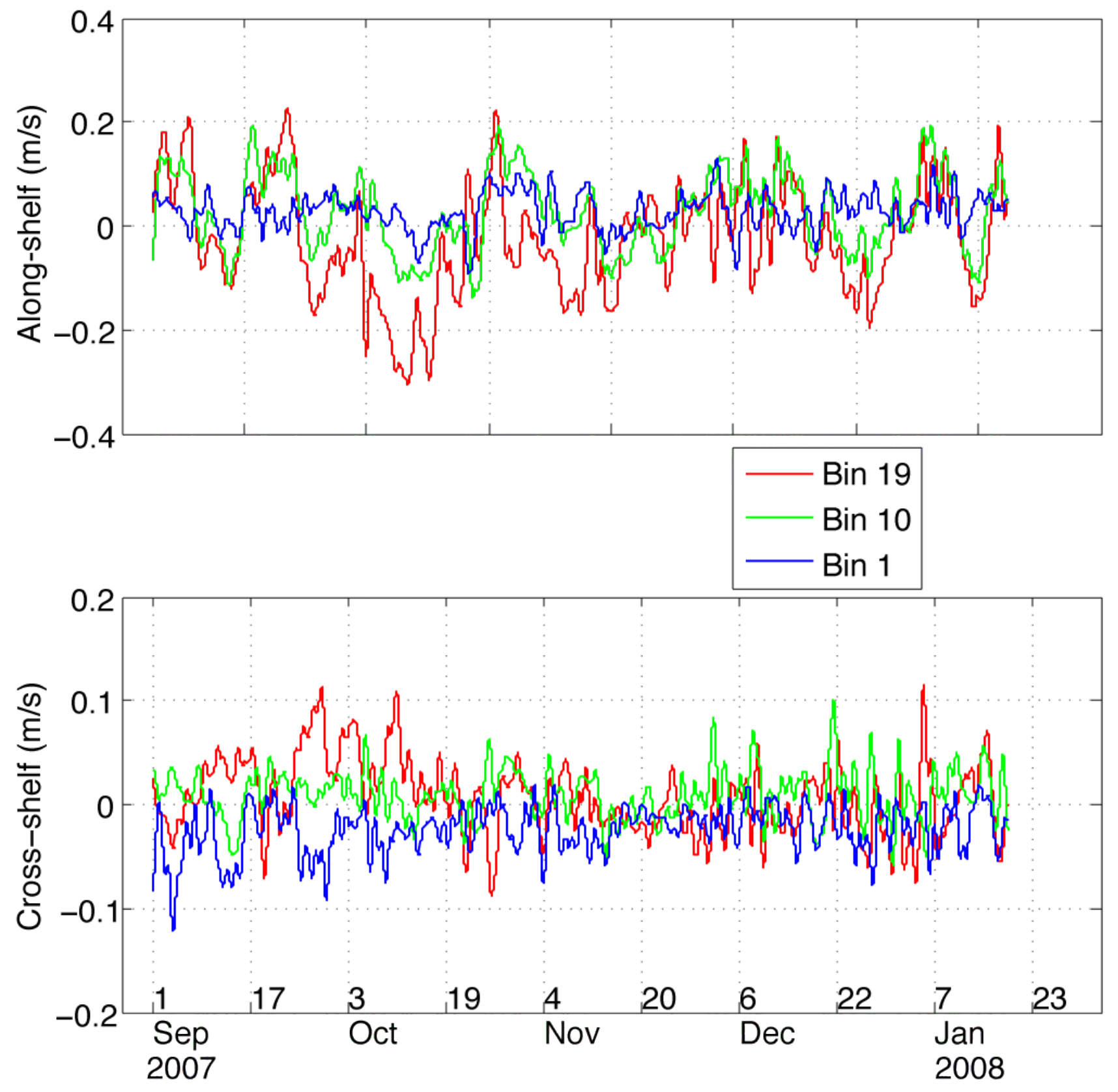

Figure 10. Time series of amplitude of the along-shelf (top panel) and cross-shelf (bottom panel) currents measured just above the seabed (bin 1), close to the seabed (bin 10), and just below the sea surface (bin 19) at Site A6 (65 m). 


\section{Site A6}
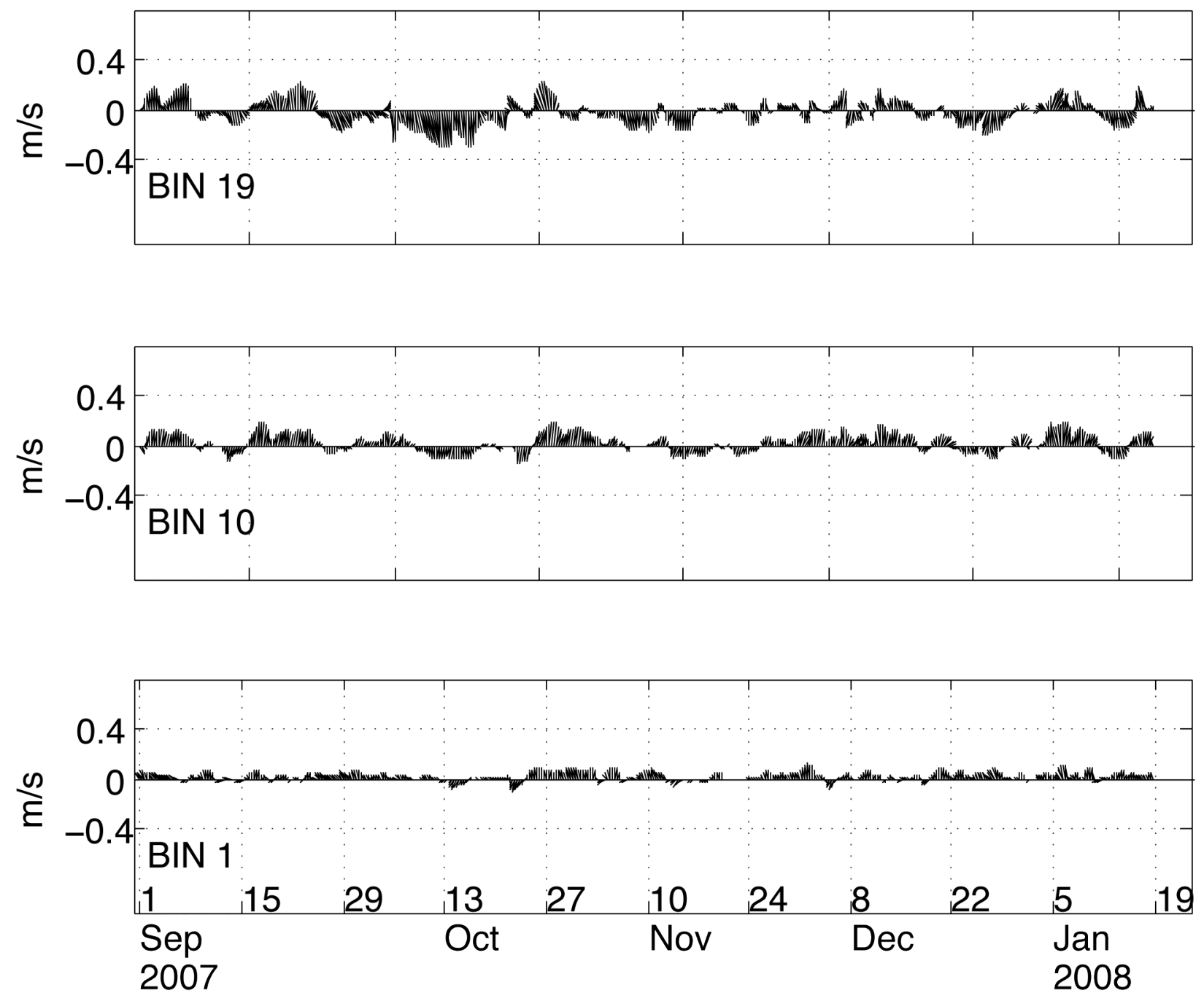

Figure 11. Vector plots of along- and cross-shelf subtidal currents measured just above the seabed (bin 1), close to the seabed (bin 10), and just below the sea-surface (bin 19) at Site A6 (65 m). 


\section{Site A7}
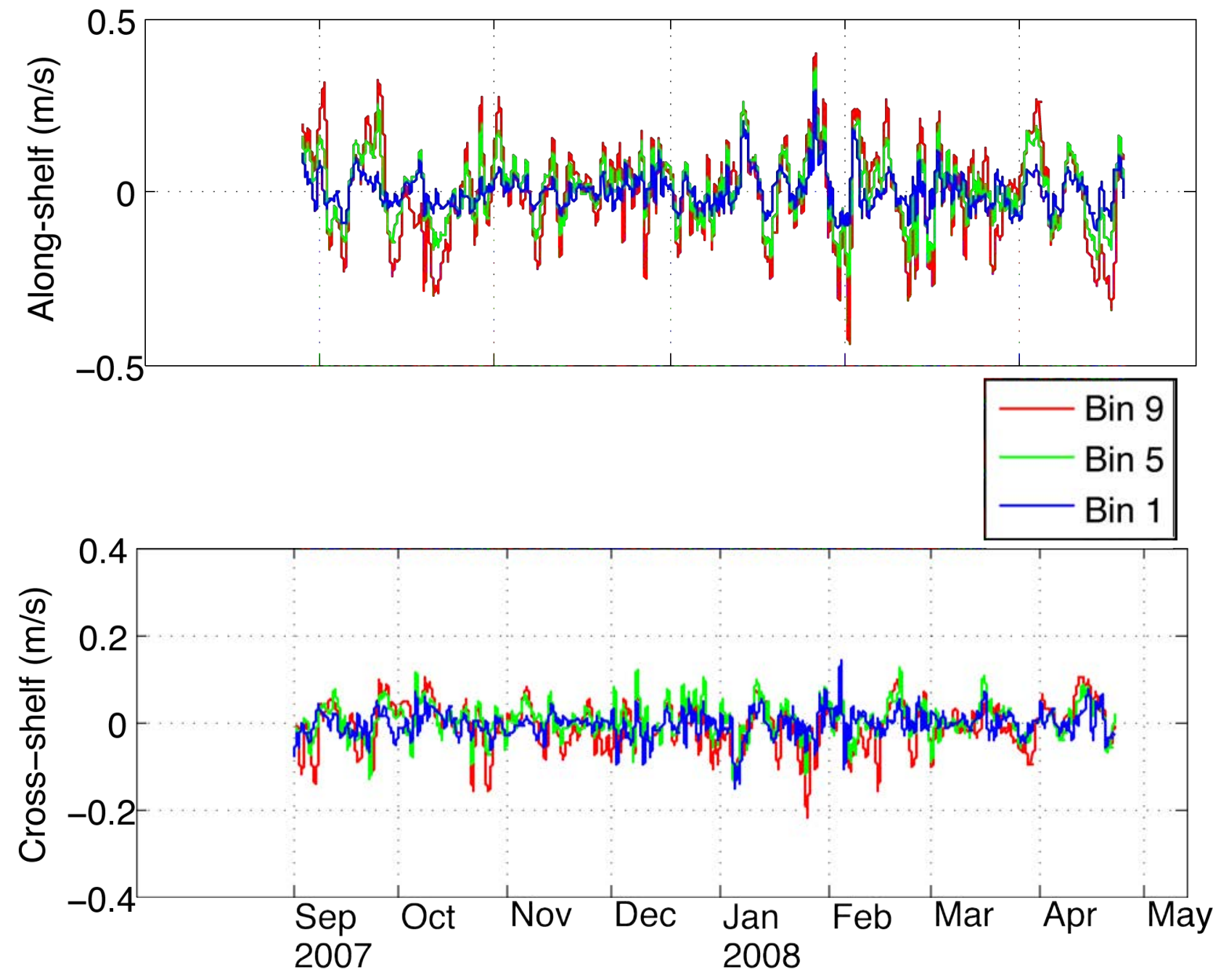

Figure 12. Time series of amplitude of the along-shelf (top panel) and cross-shelf (bottom panel) currents measured just above the seabed (bin 1), close to the seabed (bin 5), and just below the sea-surface (bin 9 ) at Site A7 (35 m). 
Site A7
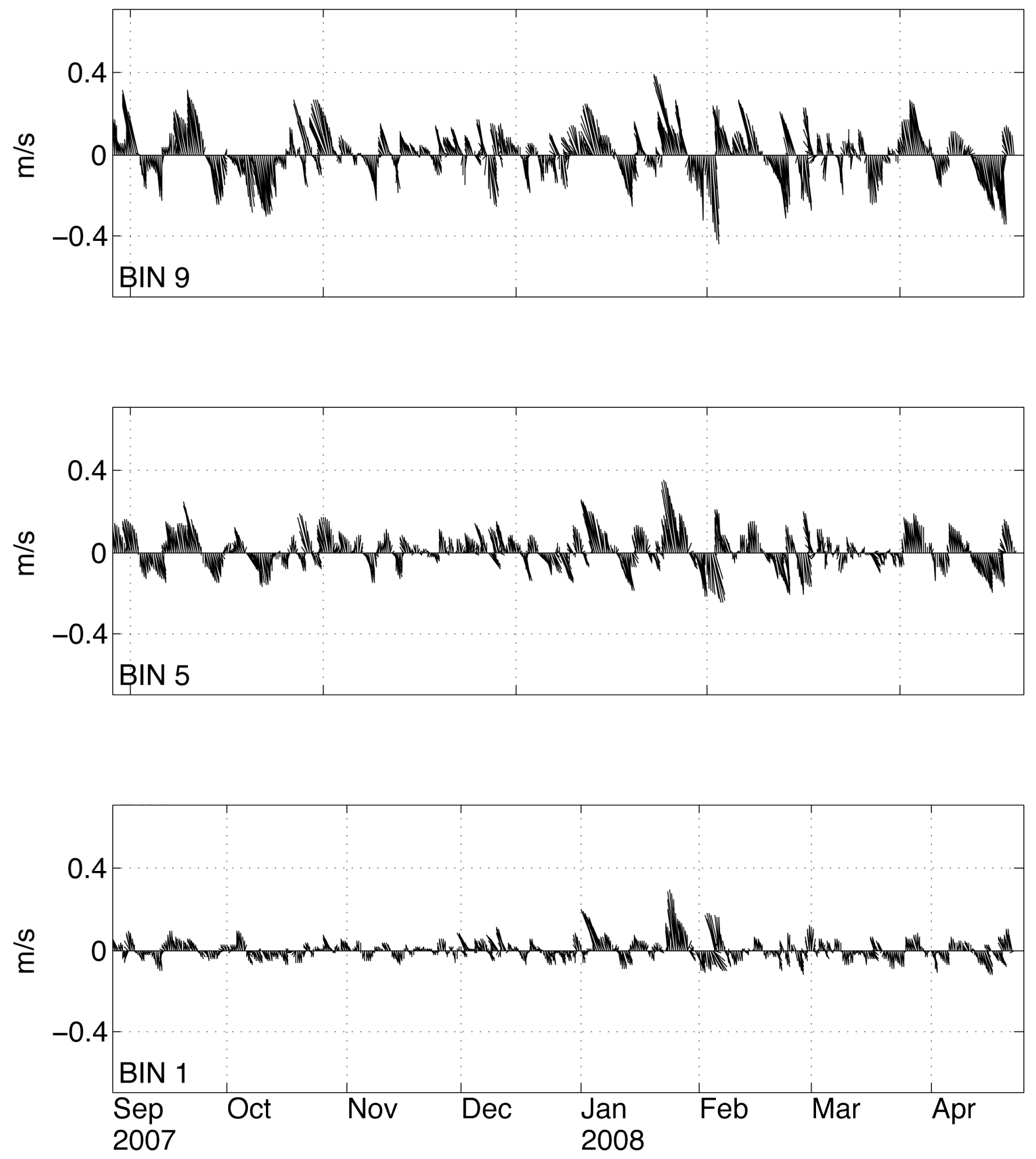

Figure 13. Vector plots of along- and cross-shelf subtidal currents measured just above the seabed (bin 1), close to the seabed (bin 5), and just below the sea surface (bin 9) at Site A7 (35 m). 
Site $\mathrm{AH}$
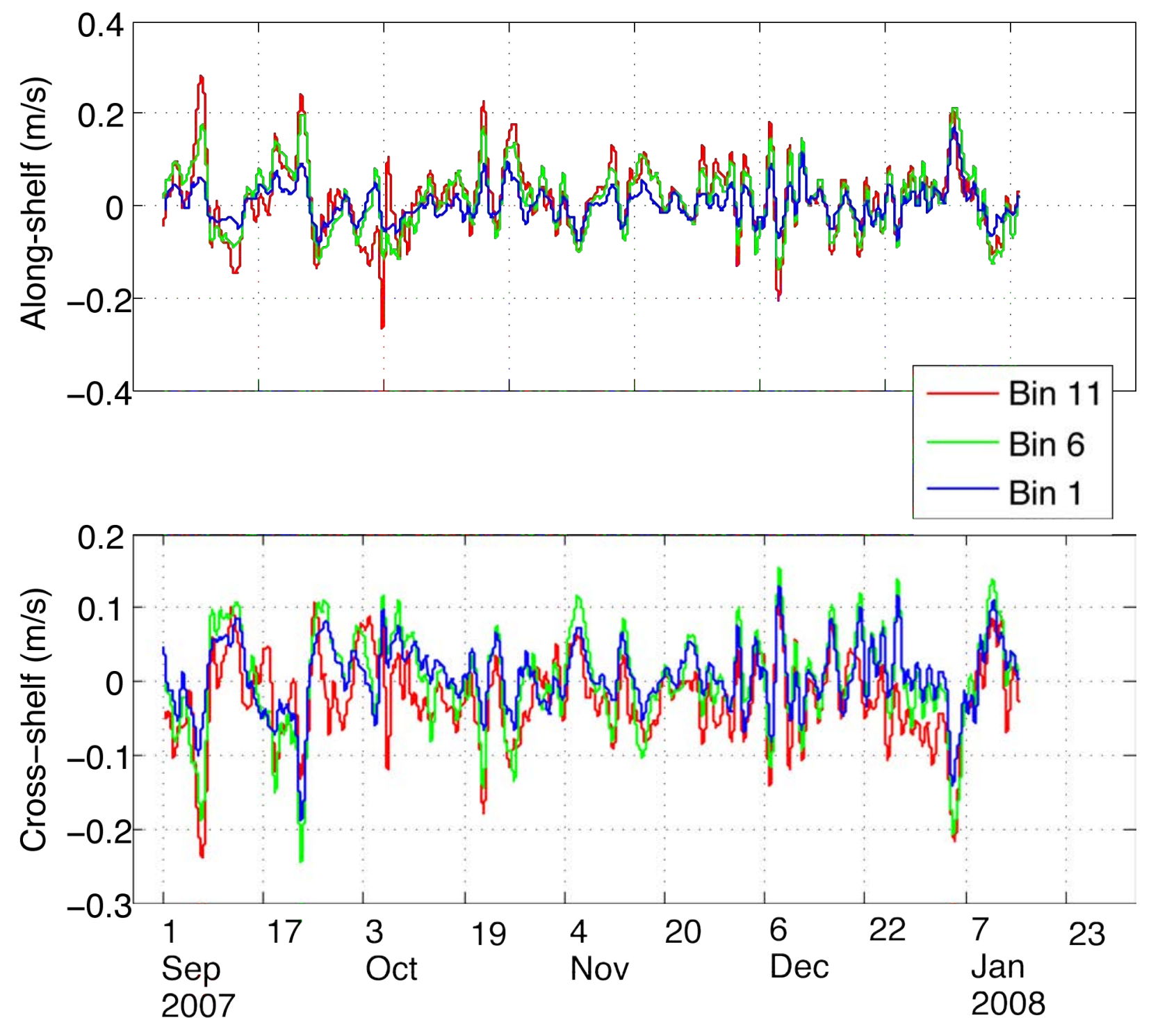

Figure 14. Time series of amplitude of the along-shelf (top panel) and cross-shelf (bottom panel) currents measured just above the seabed (bin 1), close to the seabed (bin 6), and just below the sea-surface (bin 11) at Site $\mathrm{AH}(20 \mathrm{~m})$. 


\section{Site $\mathrm{AH}$}
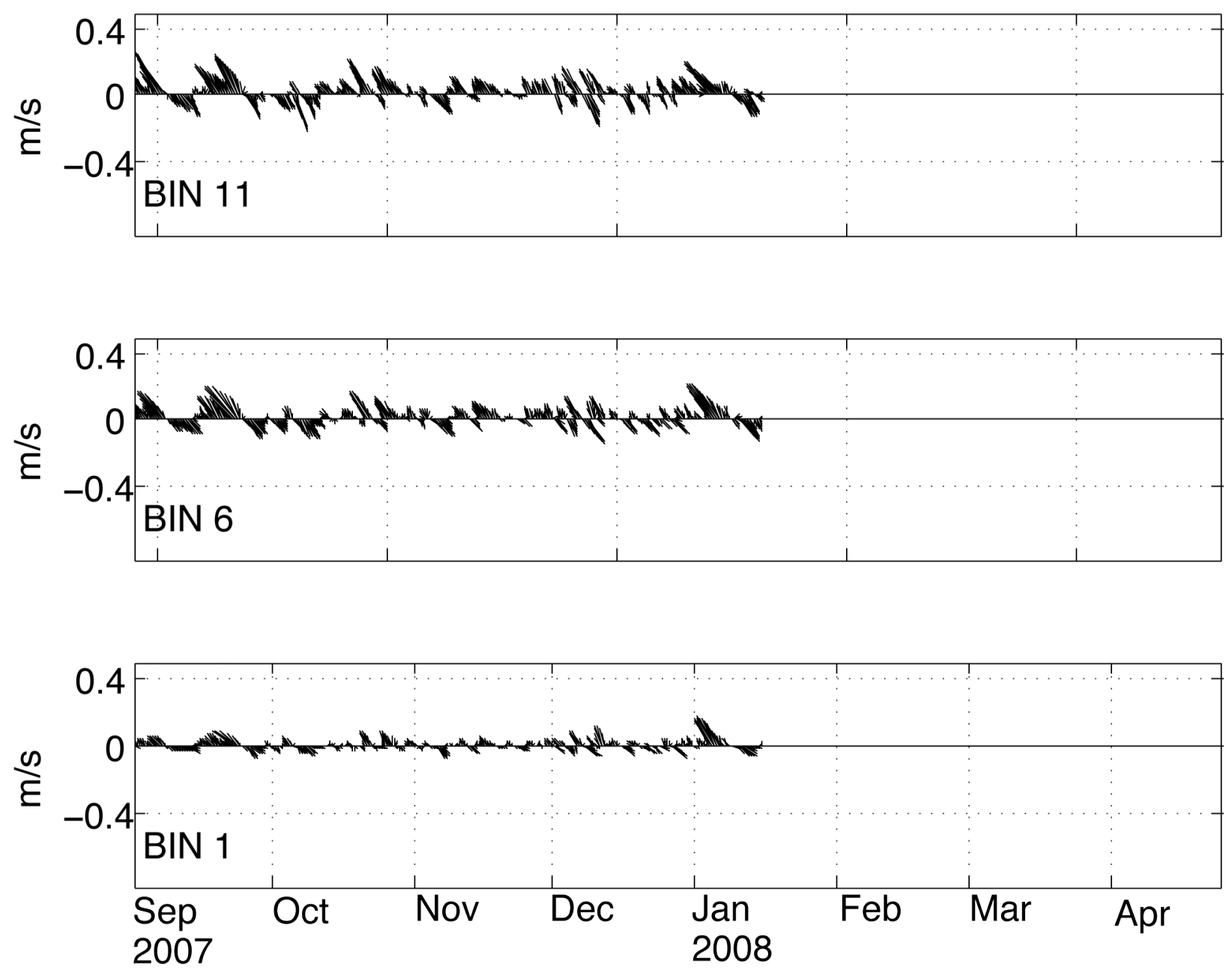

Figure 15. Vector plots of along- and cross-shelf subtidal currents measured just above the seabed (bin 1), close to the seabed (bin 6), and just below the sea-surface (bin 11) at Site AH (20 m). 


\section{Thermistor Data Files}

Thermistor moorings were deployed next to most of the ADCP moorings located on the Palos Verdes shelf and a few of the ADCP moorings within San Pedro Bay (table 2). On each of the moorings, Aquatec, Ltd., temperature loggers were attached in 3-m intervals from the seafloor to $2 \mathrm{~m}$ from the water surface. The temperature sensors were located at the center of each current bin at the adjacent ADCP. Temperature measurements were at 15-minute intervals, with an accuracy of better than $0.1 \mathrm{C}^{\circ}$. Nominal accuracy for temperature data (and the original equipment specification) was 0.1 $\mathrm{C}^{\circ}$. Final temperature logger data were organized into single .csv format files for each mooring, containing all the data for that mooring from the beginning of the study.

No changes were made to the temperature records received from LACSD. Because many temperature records had significant temporal gaps, especially at depths near the surface, the temperature records were not bridged. All temperature data records for each mooring site were put into a single netCDF data file, and ordered by depth. Column 1 in the netCDF files stores the deepest temperature record, similar to the structure used for the ADCP current record file. The shallowest temperature record is stored in the column of the netCDF file with the largest number. The depth of each sensor is also stored in that file.

The temperature data filename convention has the format "station_namePV.nc". For example, thermistor mooring Site T2 has the filename t2PV.nc.

Appendix B shows temperature plots (figs. B1-B12) for thermistor sites T1 through T9 at sites A1 through $\mathrm{A}$, and thermistor $\mathrm{TC}$ at site $\mathrm{AC}$, TE at site $\mathrm{AE}$, and $\mathrm{TG}$ at site $\mathrm{AG}$.

\section{Acknowledgments}

The Los Angeles County Sanitation Districts' Ocean Monitoring and Research Group staff were involved with evaluation and procurement of all the specialized oceanographic equipment used for the study, including ADCPs, high resolution thermistors.

As supervisor of the OMRG, Joe Meistrell managed the Palos Verdes Flow Study from its inception. Joe oversaw the selection of oceanographic equipment and worked with the Sanitation Districts' management to obtain Board approval for its purchase. Joe also sought the advice of outside experts, notably Luciano Meiorin of Parsons. Senior Biologist Fred Stern was also involved with this project from the beginning, and supervised all fieldwork throughout the nine years of the study, including maintaining complex oceanographic equipment. The coordination between Fred and Senior Boat Captain Steve Gregson, often under difficult conditions, was indispensable to the success of the study. Environmental Scientist Alex Steele managed data processing and archiving and report preparation during the study. The authors would like to thank Andrew Stevens and Christopher Sherwood of the USGS Coastal and Marine Geology Program for their thoughtful insights and comments on this manuscript. 


\section{References Cited}

Reference, 2000, National water quality inventory-1998 report, U.S. Environmental Protection Agency Report EPA-841-F-00-006, 45 p.

Anderson, N.O., 1974, On the calculation of filter coefficients for maximum entropy spectral analysis: Geophysics, v. 39, p. 69-72.

Los Angeles County Sanitation Districts, 2002, Palos Verdes flow study 2000-2001: Data Report.

Los Angeles County Sanitation Districts, 2006, Palos Verdes flow study 2000-2006: Data Report.

Los Angeles County Sanitation Districts, 2008, Palos Verdes flow study 2000-2006: Data Report.

Montgomery, E.T., Martini, M.A., Lightsom, F.L., and Butman, B., 2008, Documentation of the U.S. Geological Survey oceanographic time series measurement database: U.S. Geological Survey OpenFile Report 2007-1194.

Noble, M.A., Rosenberger, K.J., Xu, J.P., Signell, R.P., and Steele, A., 2008, Connections among the spatial and temporal structures in tidal currents, internal bores, and surficial sediment distributions over the shelf off Palos Verdes, California: U.S. Geological Survey Scientific Investigations Report 2008-5094 [available on the World Wide Web at http://pubs.usgs.gov/sir/2008/5094 ].

Rosenberger, K., Noble, M.A., Sherwood, C.R., Martini, M.A., Ferreira, J.T., and Montgomery, E., 2010, Palos Verdes shelf oceanographic study data report for observations, December 2007-April 2008: U.S. Geological Survey Open-File Report 2010-1240 [available on the World Wide Web at http://pubs.usgs.gov/of/2010/1240/].

Science Applications International Corporation (SAIC), 2004, Analysis of moored oceanographic data acquired on the Palos Verdes Shelf by the LACSD during the period from November 2000 to August 2003: Prepared for U.S. Army Corps of Engineers, Santa Ana Dams Resident Office, and U.S. Environmental Protection Agency, Region IX: Newport, Rhode Island, SAIC Report 659, 123 p.

Science Applications International Corporation (SAIC), 2005, Data report for the summer 2004 oceanographic measurement program conducted on the Palos Verdes Shelf: Prepared for U.S. Environmental Protection Agency, Region IX: Newport, Rhode Island, SAIC Report 694, 40 p.

Science Applications International Corporation (SAIC), 2009, Orange County Sanitation District ocean current studies: Analysis of inter- and intra-annual variability in coastal currents: Prepared for Orange County Sanitation District: San Diego, California, SAIC Report, 62 p.

Steele, A., 2009, Palos Verdes flow study: 2000-2008: Los Angeles County Sanitation Districts Final Report.

Xu, J.P., Lightsom, F.L., Noble, M.A., and Denham, C., 2002, CMGTooL user's manual: U.S. Geological Survey Open-File Report 2002-19 [Available on the World Wide Web at http://geopubs.wr.usgs.gov/open-file/of02-19 ]. 


\section{Appendix A. Matlab Scripts Used to Process Data}

Figure A1. The cdl template used by netCDF operators to define a new netCDF file.

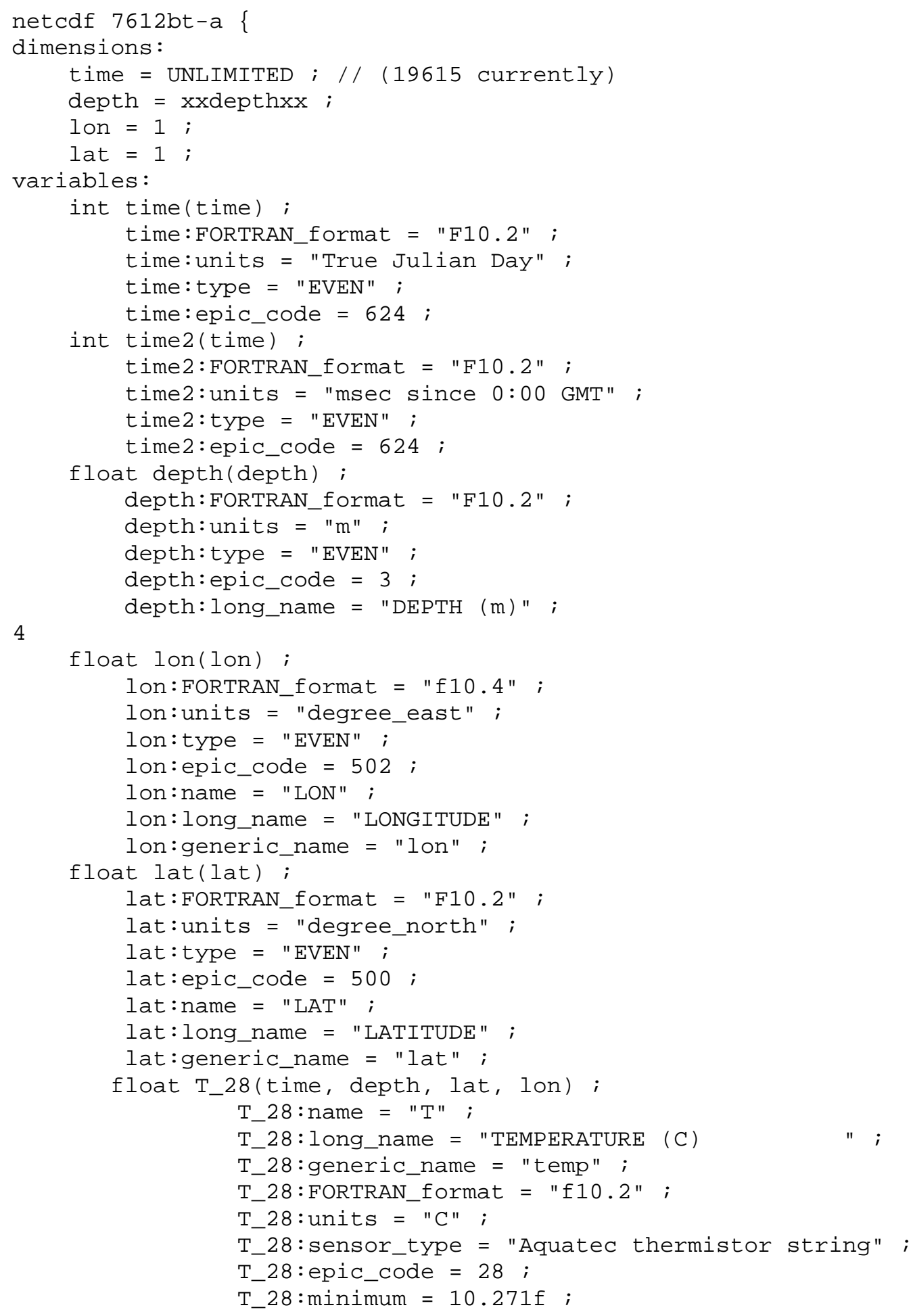




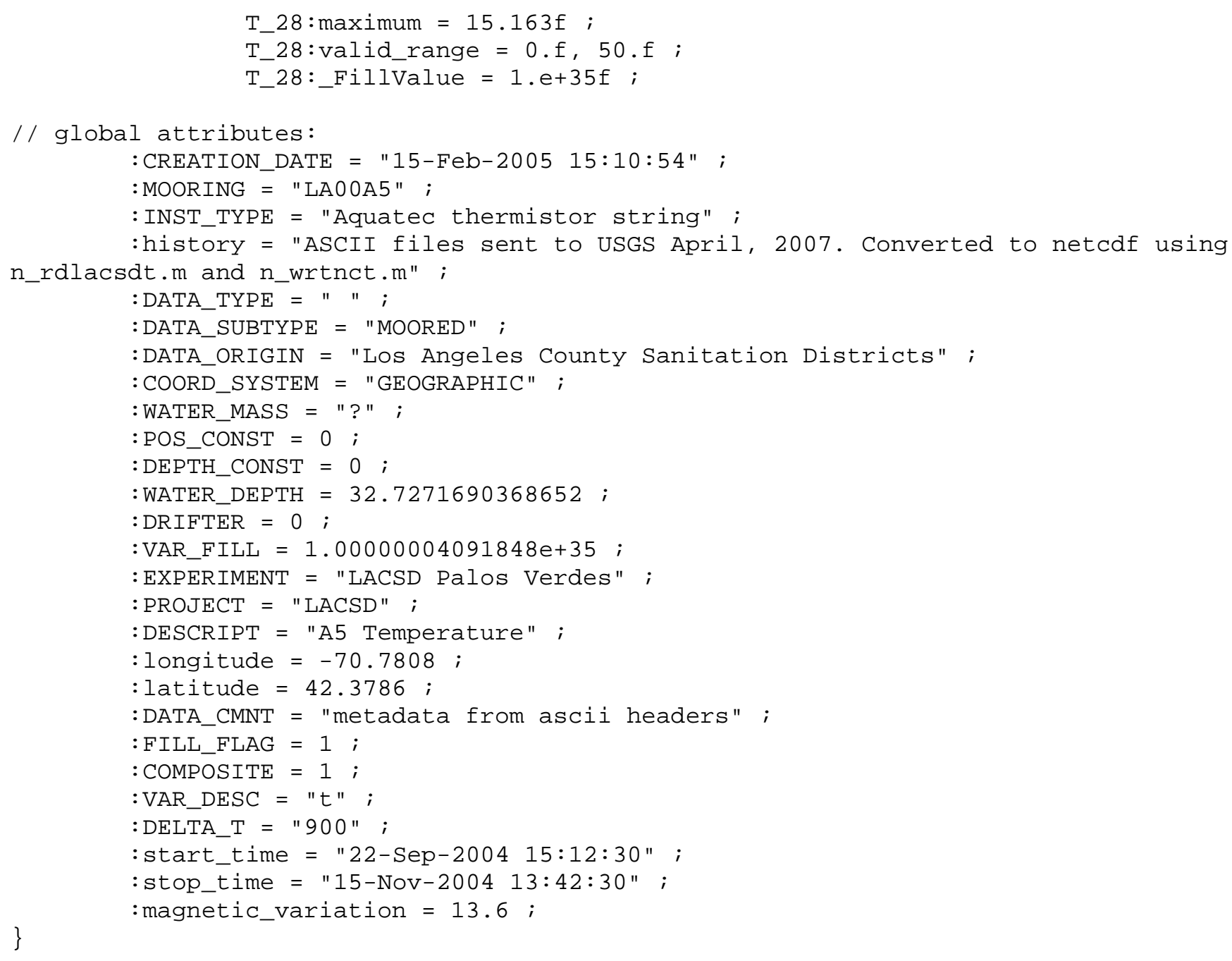

Figure A2. The Matlab processing script to read in the LACSD current meter data in the format provided to USGS by LACSD, and generate a matlab data file.

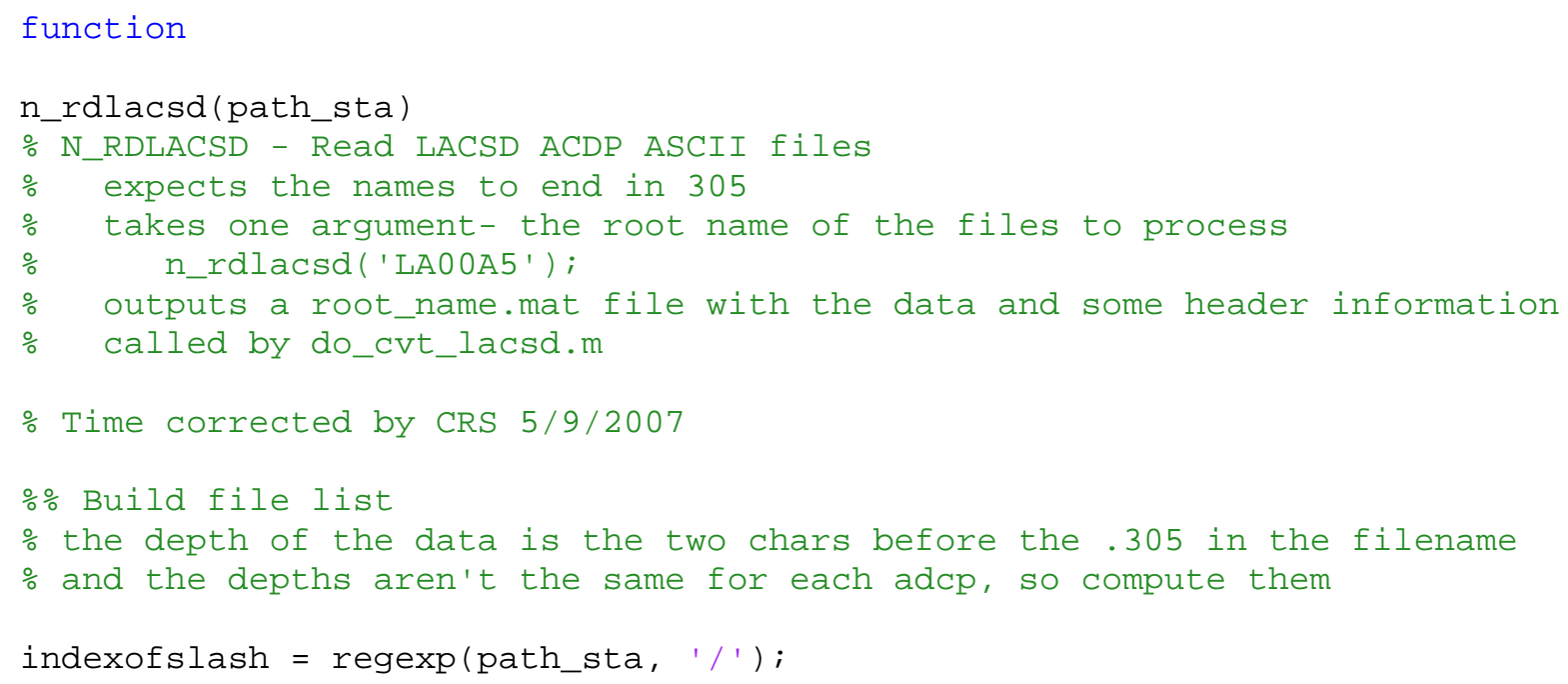




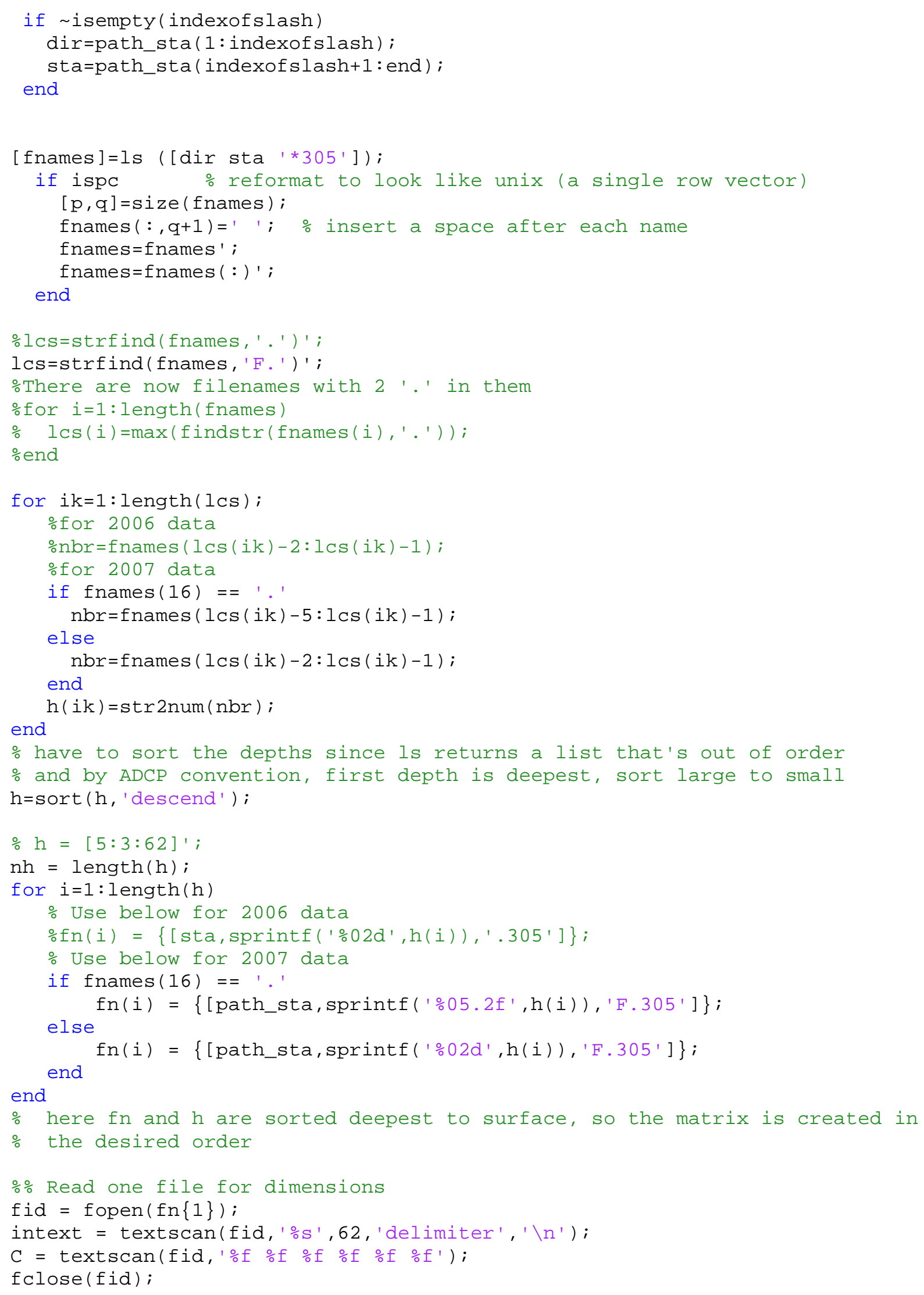




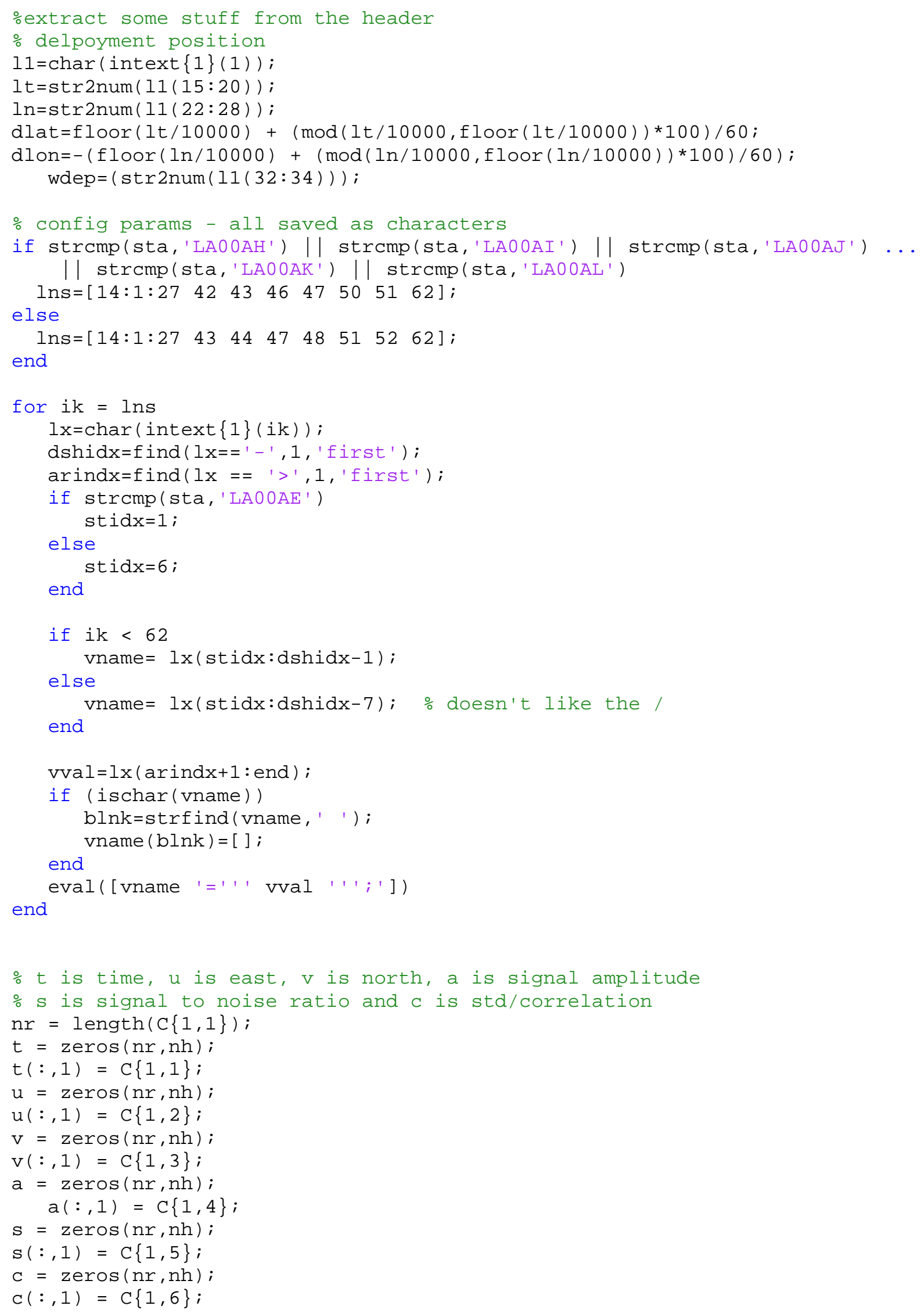




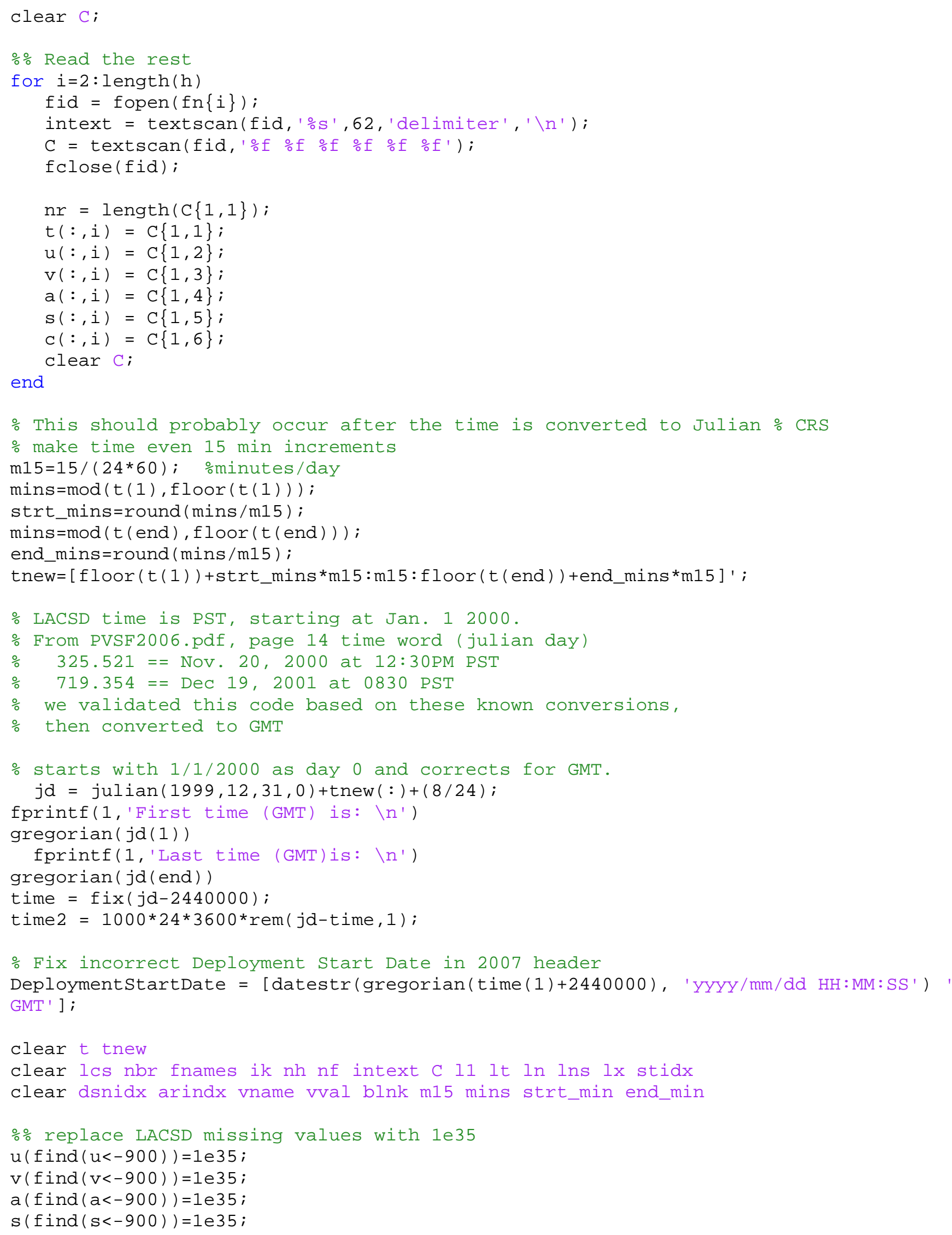




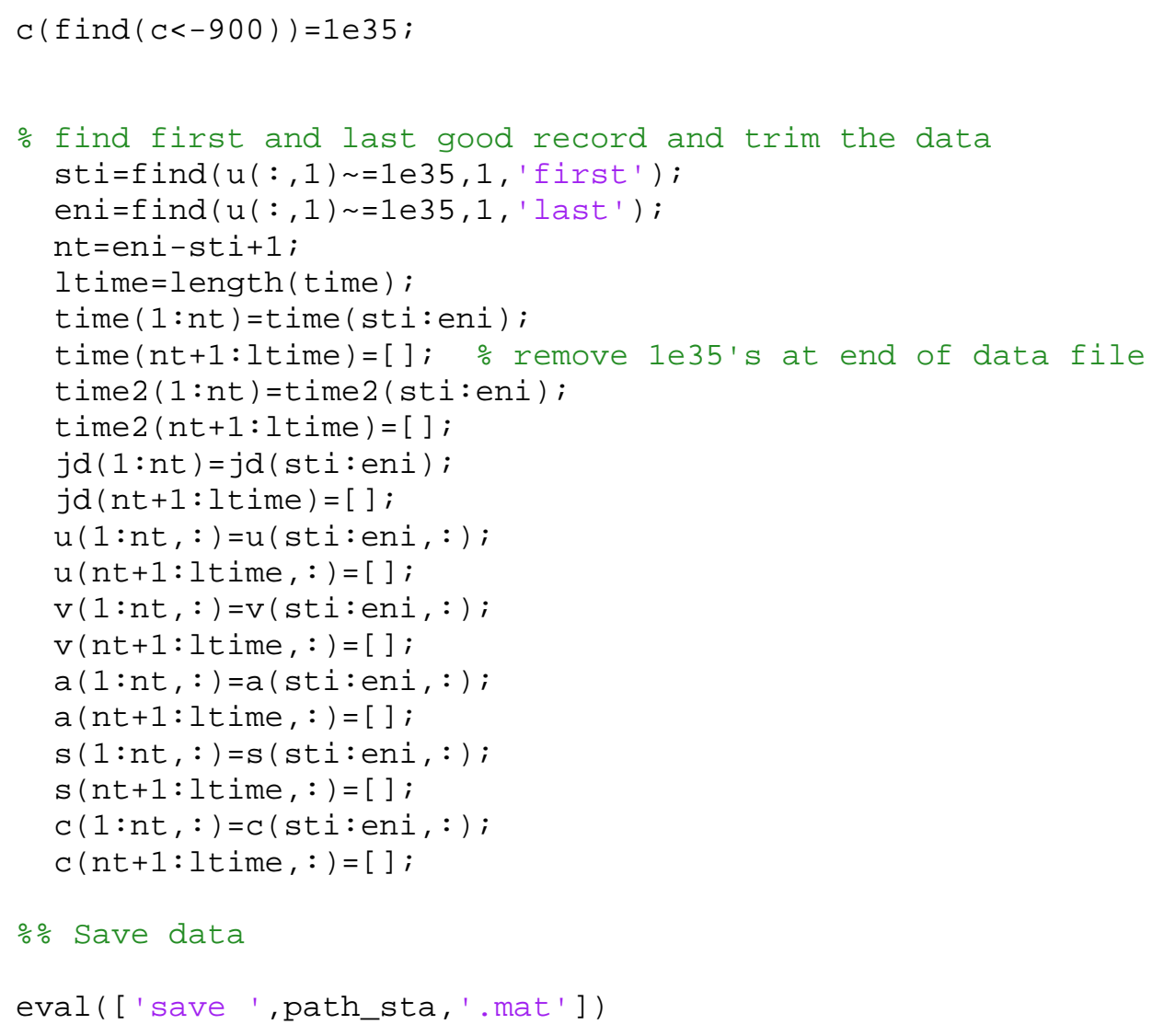


Figure A3. The Matlab processing script to scan the LACSD current meter data for obviously erroneous data, fill in the points with flag values, and write the netCDF file.

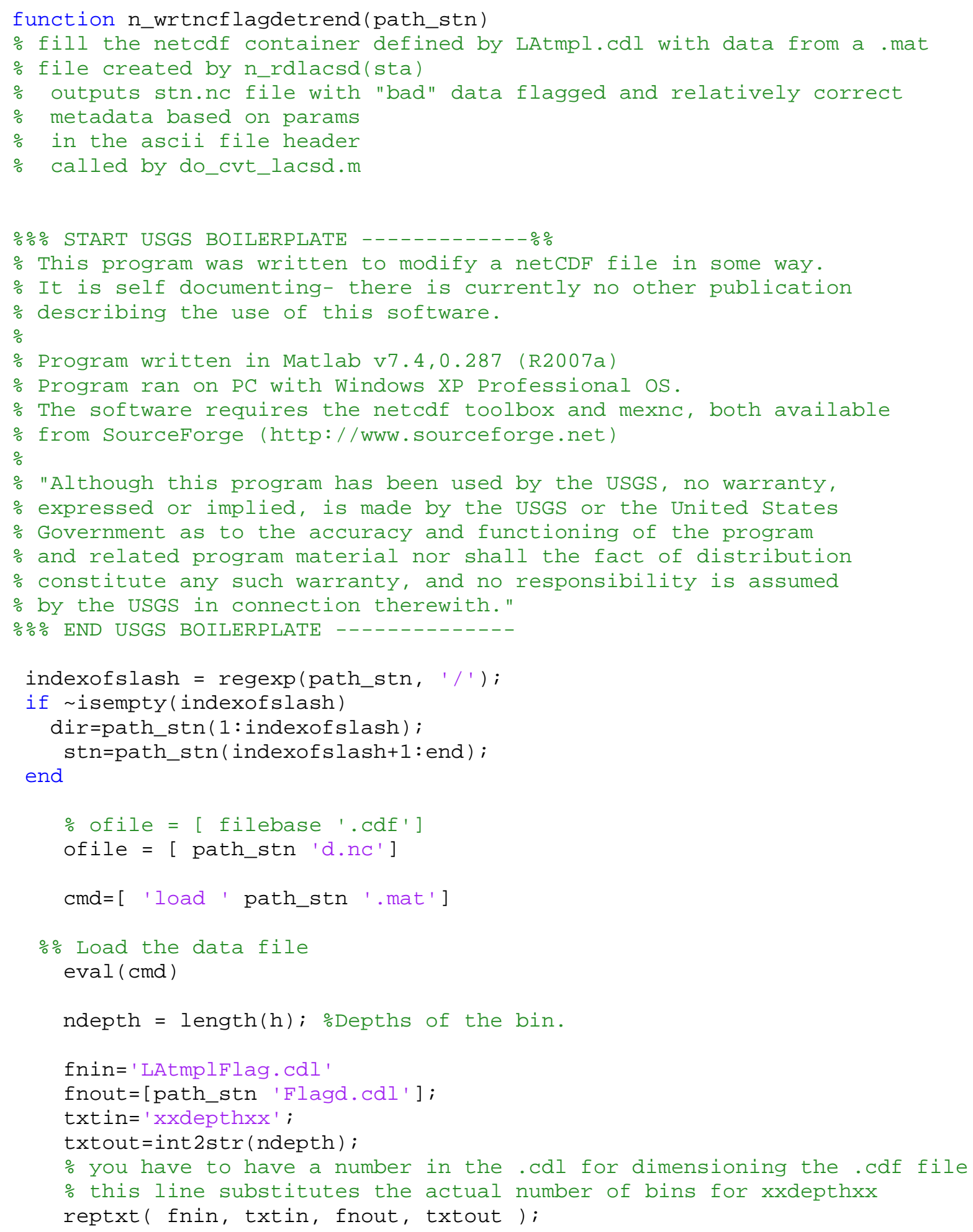




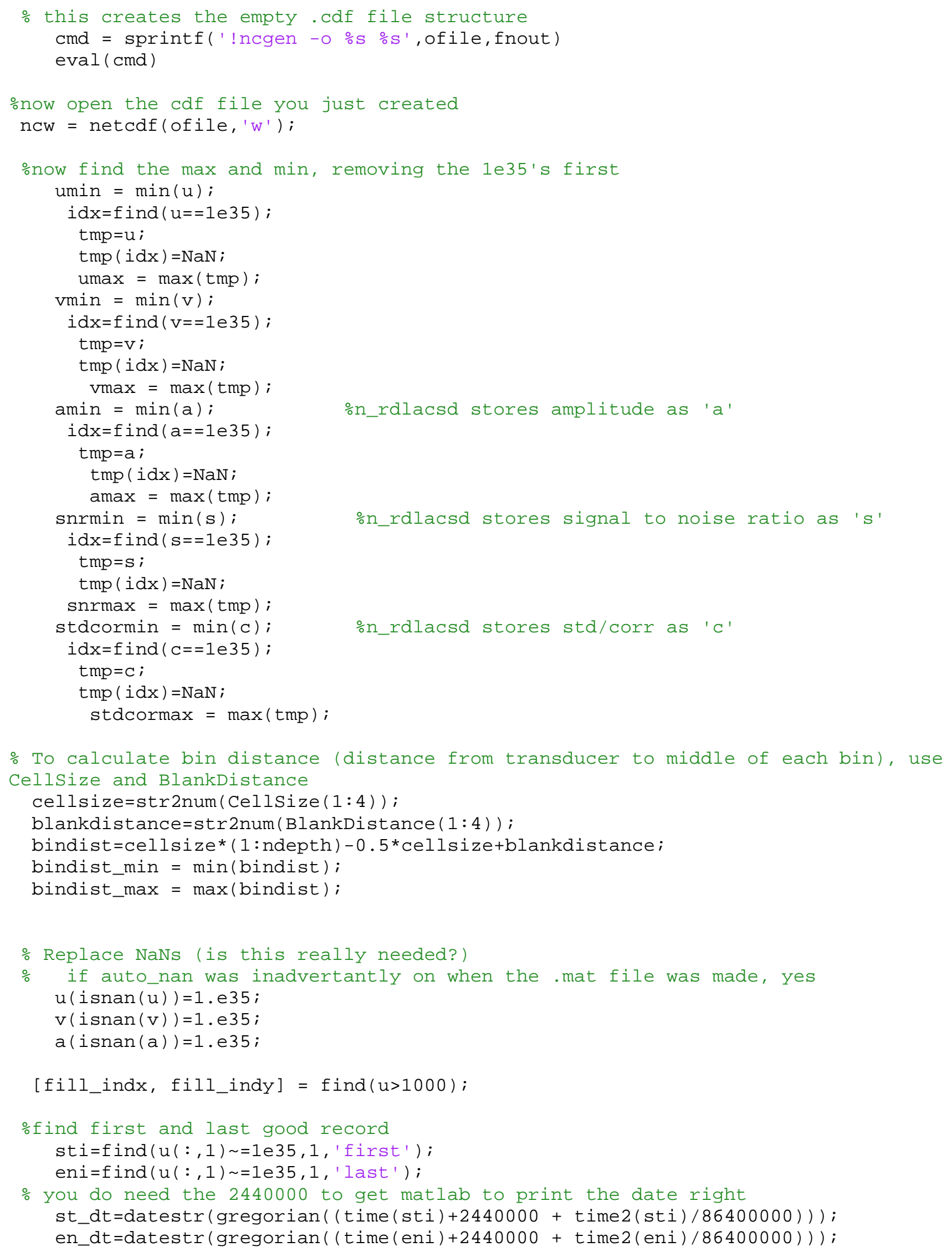

$\left[f i l l \_i n d x, f i l l \_i n d y\right]=f i n d(u>1000)$;

\%find first and last good record

sti=find $(u(:, 1) \sim=1 e 35,1$, 'first ' );

eni=find (u(: 1) =1e35, 1, ' last' );

$\%$ you do need the 2440000 to get matlab to print the date right

st_dt=datestr (gregorian ( (time $(s t i)+2440000+\operatorname{time2}($ sti $) / 86400000)))$;

en_dt=datestr $($ gregorian $((\operatorname{time}($ eni $)+2440000+\operatorname{time} 2($ eni $) / 86400000)))$; 
$\%$ Find spikes in speed and flag them

jdadv $=$ time $+($ time $2 / 86400000) ;$ depthadv $=\mathrm{h}$;

$\operatorname{dtA}=(j \operatorname{dadv}(2)-j \operatorname{dadv}(1)) * 24 ;$

$\mathrm{u}(\mathrm{u}>1000)=\mathrm{NaN} ; \mathrm{v}(\mathrm{v}>1000)=\mathrm{NaN}$;

Ubr $=$ cmgbridge $(u, 1 / \mathrm{dtA}, 12 / \mathrm{dtA}, 10000) ; \mathrm{Vbr}=\operatorname{cmgbridge}(\mathrm{v}, 1 / \mathrm{dtA}, 12 / \mathrm{dtA}, 10000) ;$

$\operatorname{spd}=\operatorname{sqrt}(U b r . \wedge 2+\operatorname{Vbr} . \wedge 2)$;

\%ind $=$ find $(j$ dadv $>=$ sti\&jdadv $<=$ eni $)$;

spd $=\operatorname{spd}($ sti:eni, : );

jdadv = jdadv(sti:eni);

$\%[N, M]=\operatorname{size}(U b r) ;$

$[N, M]=\operatorname{size}($ spd $)$;

length_run_mean = 13;

STD_limit $=3.75$;

$\%$ Use values below for testing, less bins to process (for skip $=2$ skip every other bin), $M=10$ only does the first 10 bins

skip $=1$;

$\% \mathrm{M}=10 ;$ 


\begin{tabular}{llllllll|}
10 & 12 & 14 & 16 & 18 & 20 & 22 & 24 \\
\hline & 1 & 1 & 1 & 1 & 1 & 1 & \\
\hline
\end{tabular}

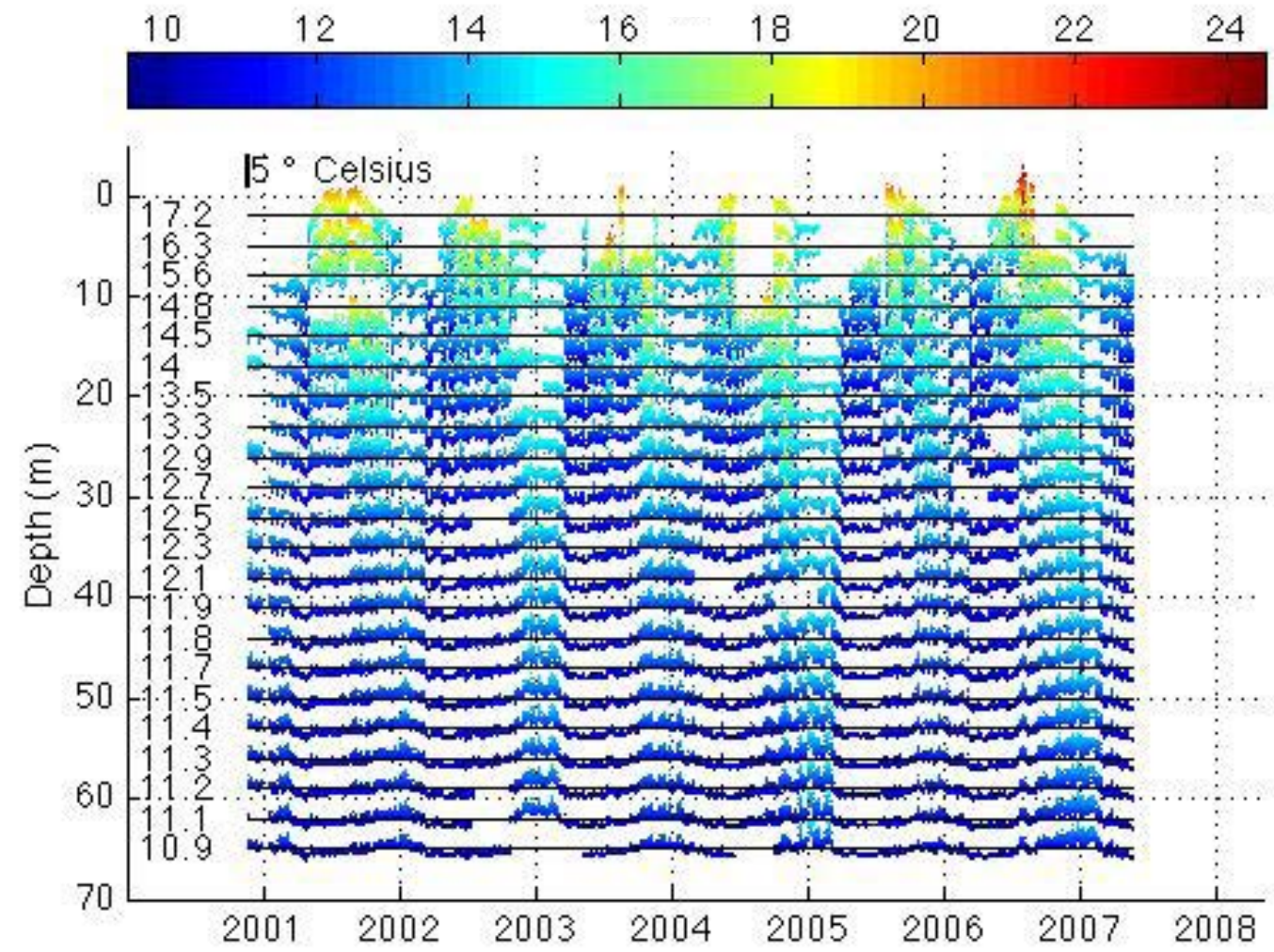

Figure B1. Temperature plots from thermistor T1 at Site A1. 


\begin{tabular}{llllllll|}
10 & 12 & 14 & 16 & 18 & 20 & 22 & 24 \\
\hline & 1 & 1 & 1 & 1 & & \\
\hline
\end{tabular}

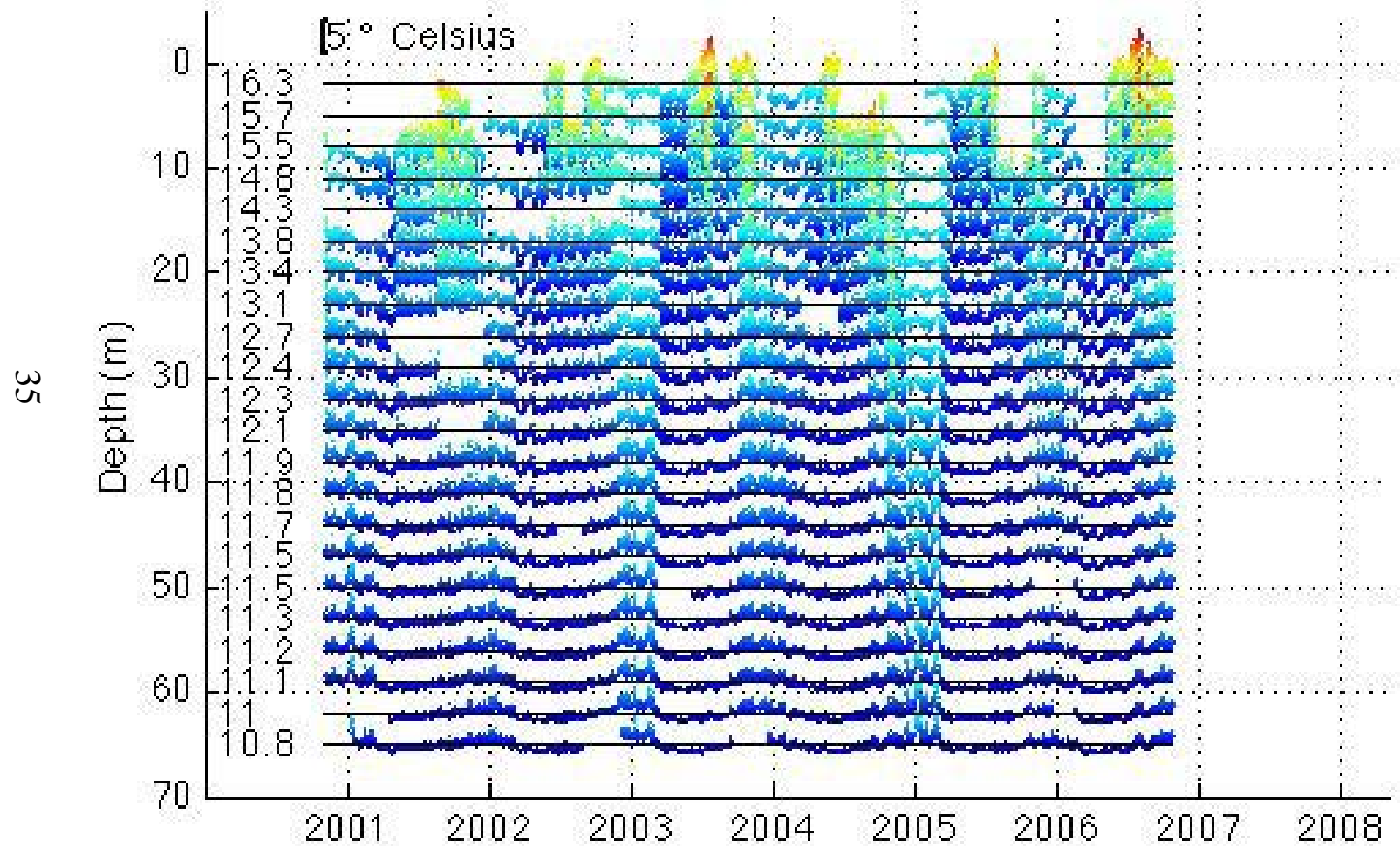

Figure B2. Temperature plots from thermistor T2 at Site A2. 


\begin{tabular}{llllllll}
10 & 12 & 14 & 16 & 18 & 20 & 22 & 24 \\
\hline & 1 & 1 & 1 & 1 & 1 &
\end{tabular}

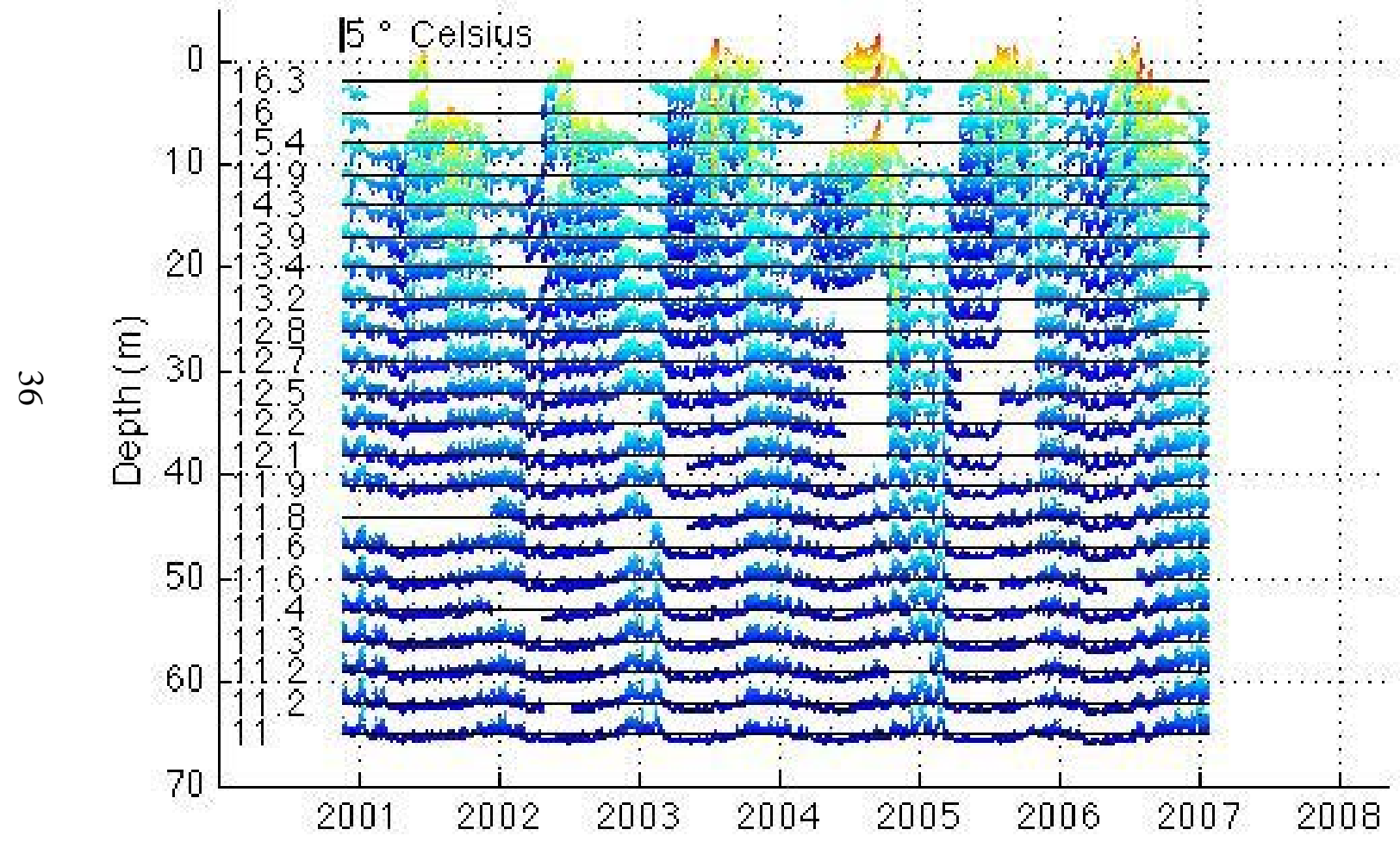

Figure B3. Temperature plots from thermistor T3 at Site A3. 


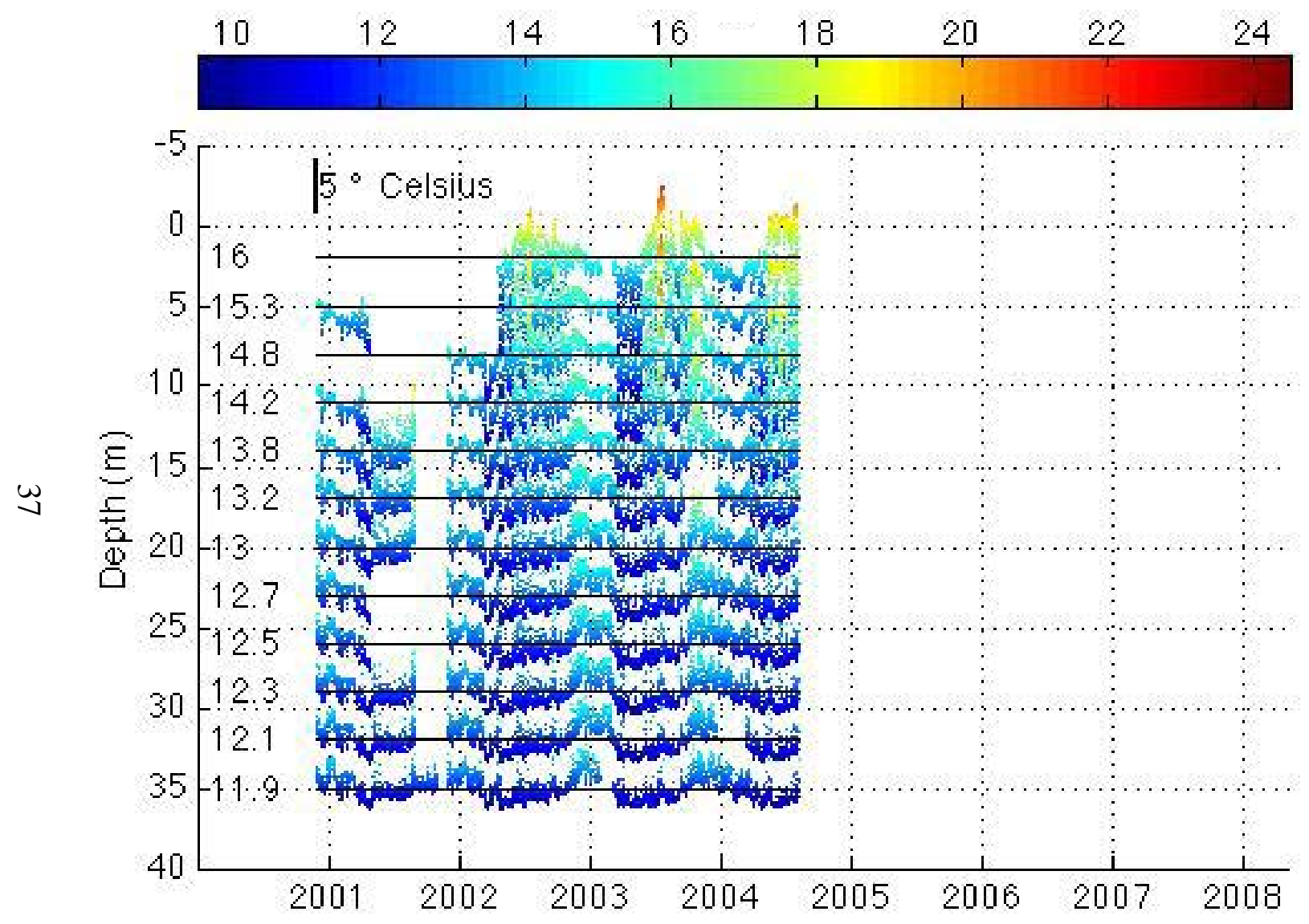

Figure B4. Temperature plots from thermistor T4 at Site A4. 


\begin{tabular}{llllllll}
10 & 12 & 14 & 16 & 18 & 20 & 22 & 24 \\
\hline & 1 & 1 & 1 & 1 & & \\
\hline
\end{tabular}

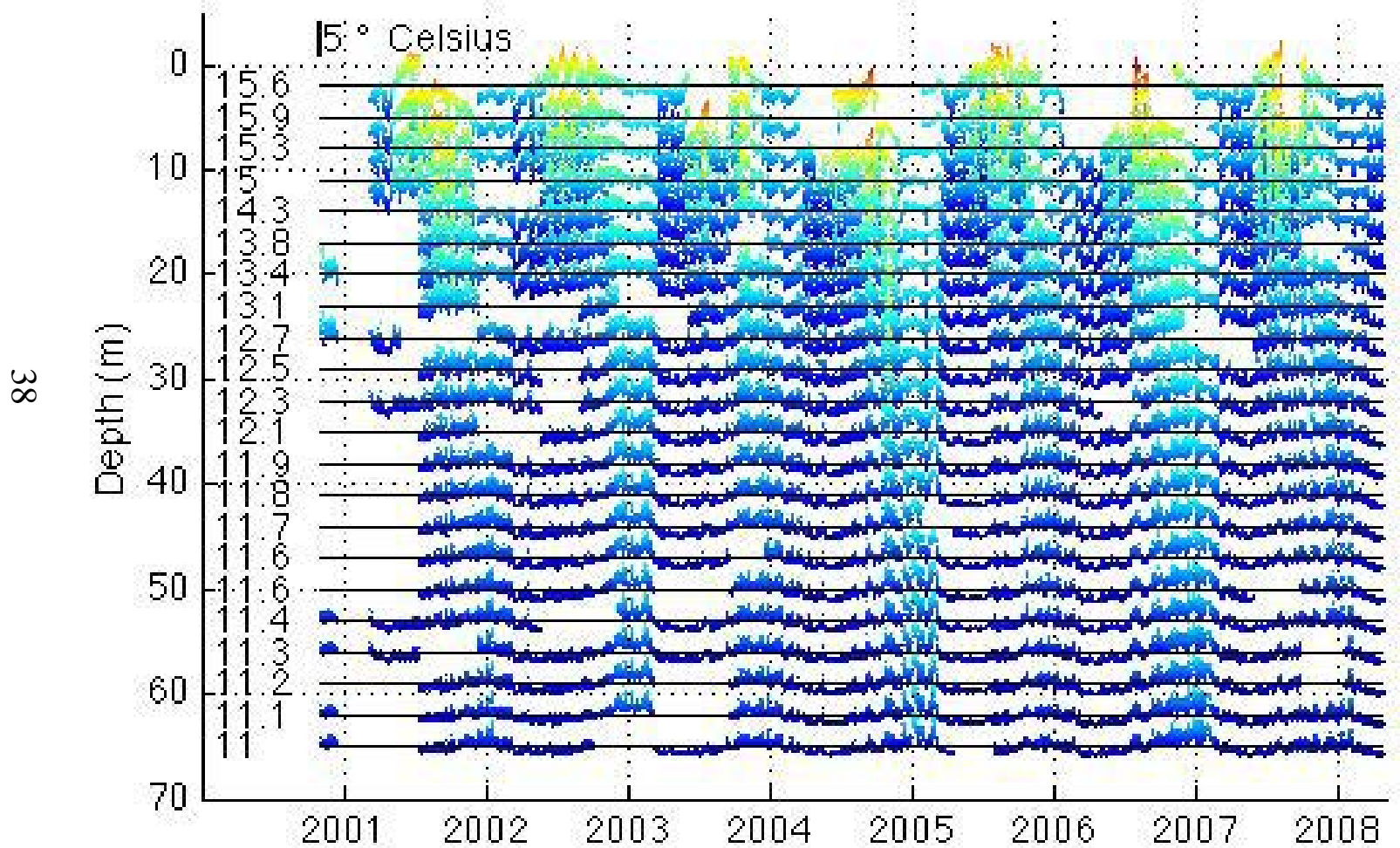

Figure B5. Temperature plots from thermistor T5 at Site A5. 


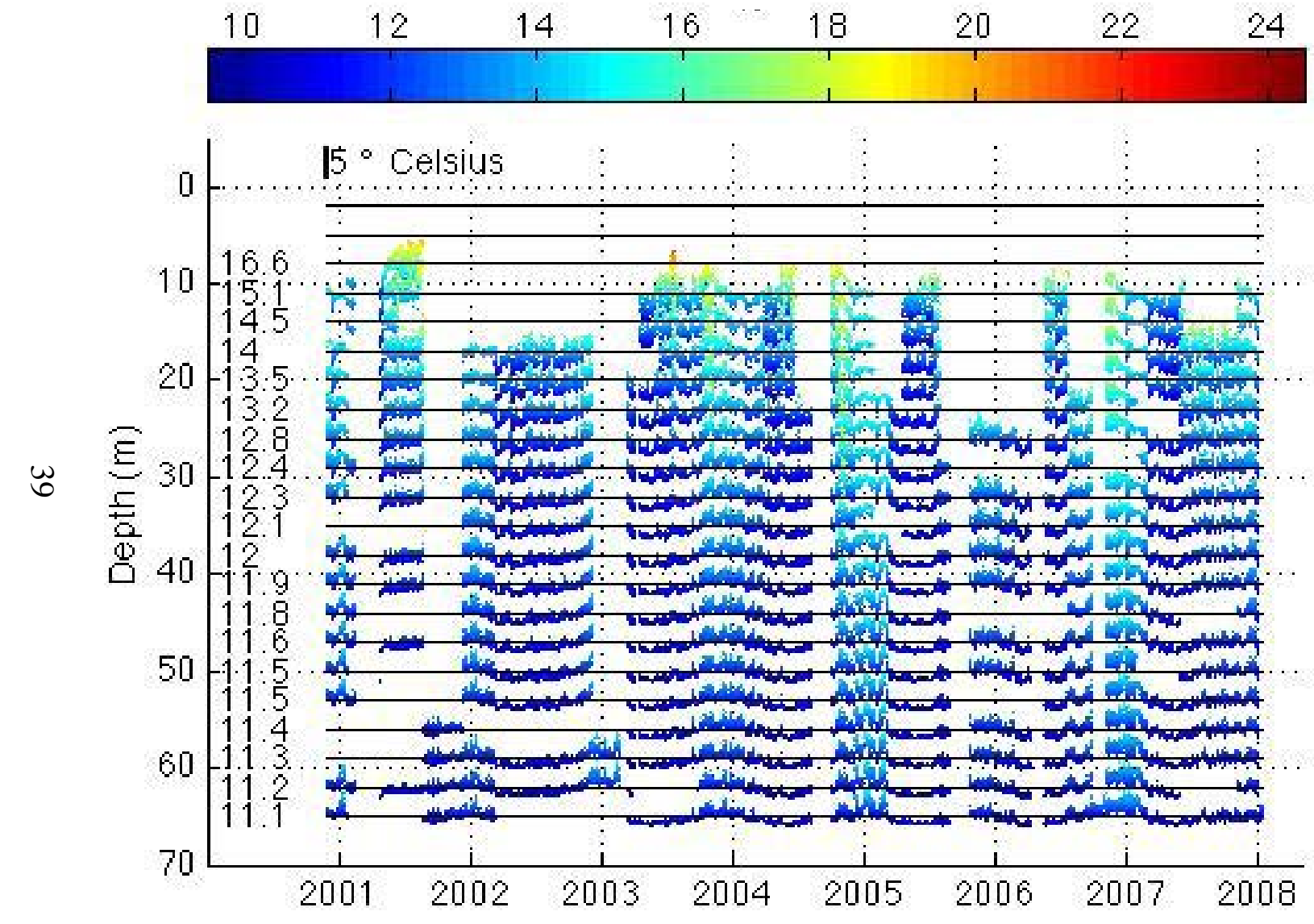

Figure B6. Temperature plots from thermistor T6 at Site A6. 


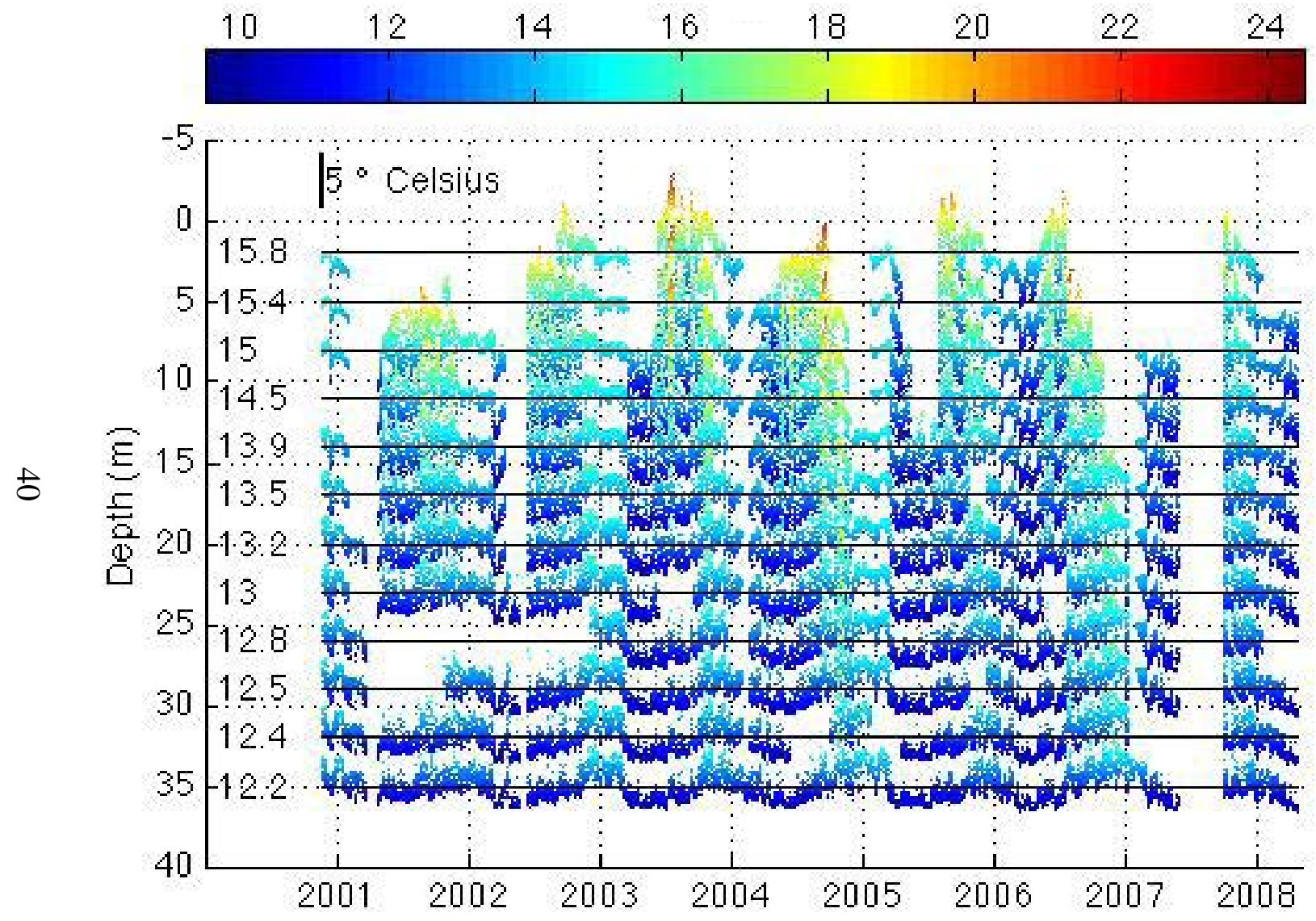

Figure B7. Temperature plots from thermistor T7 at Site A7. 


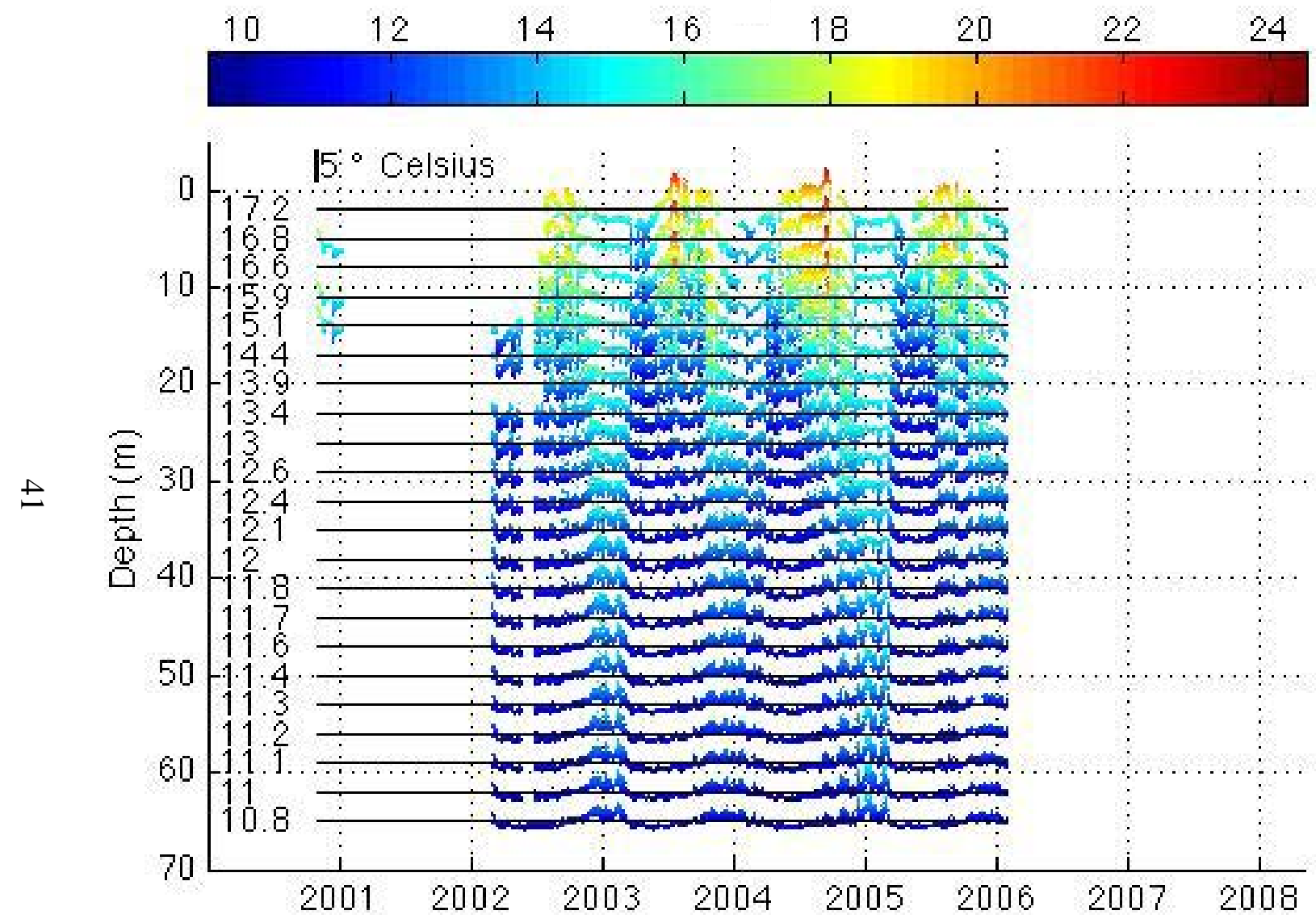

Figure B8. Temperature plots from thermistor T8 at Site A8. 


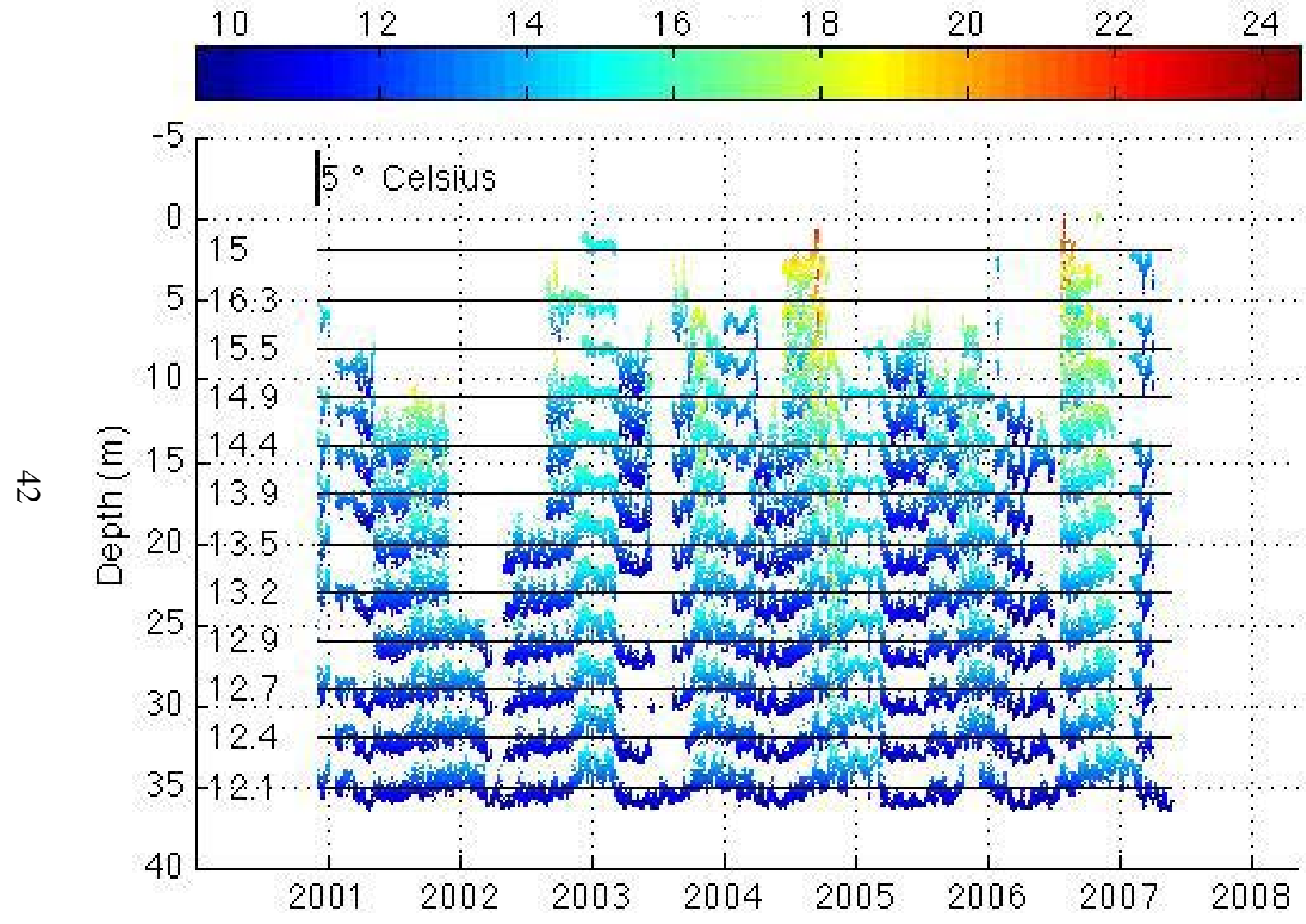

Figure B9. Temperature plots from thermistor T9 at Site A9. 


\begin{tabular}{llllllll}
10 & 12 & 14 & 16 & 18 & 20 & 22 & 24 \\
\hline & 1 & 1 & 1 & 1 & & \\
\hline & & 1 & 1 & 1
\end{tabular}

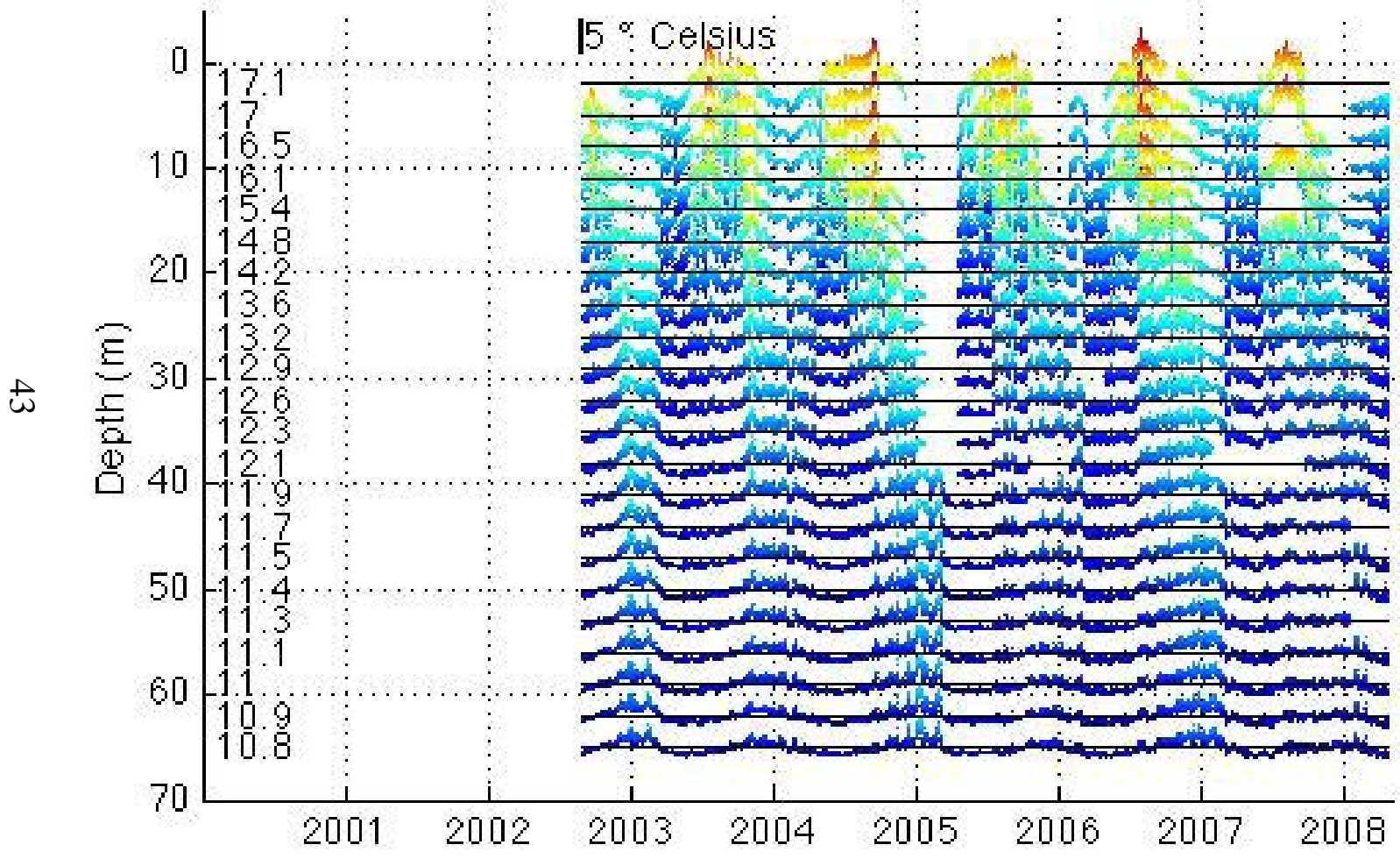

Figure B10. Temperature plots from thermistor TC at Site AC. 


\begin{tabular}{llllllll}
10 & 12 & 14 & 16 & 18 & 20 & 22 & 24 \\
\hline & 1 & 1 & 1 & 1 & 1 & \\
\hline
\end{tabular}

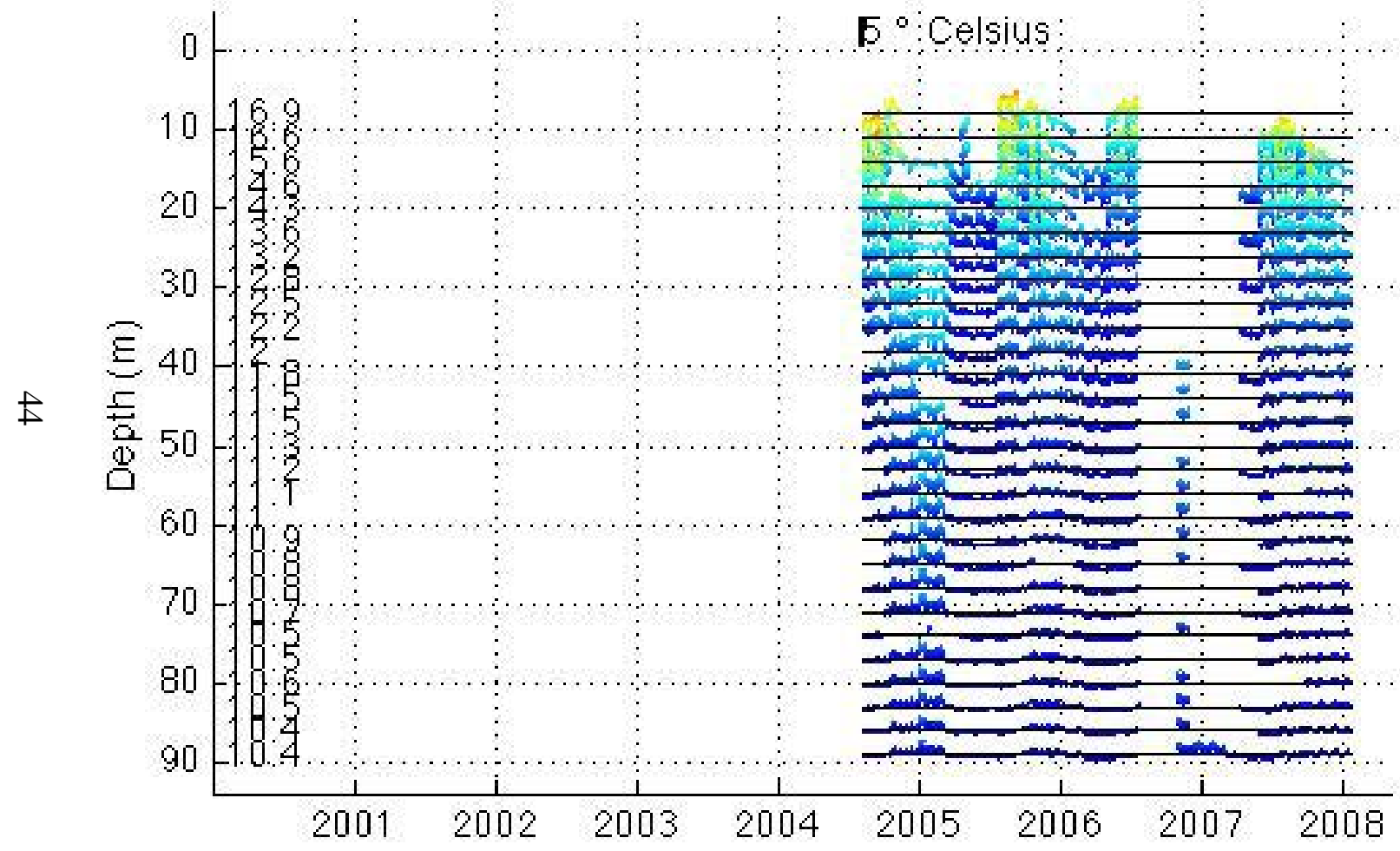

Figure B11. Temperature plots from thermistor TE at Site AE. 


\begin{tabular}{lllllllll}
10 & 12 & 14 & 16 & 18 & 20 & 22 & 24 \\
\hline & 1 & 1 & 1 & 1 & 1 & \\
\hline
\end{tabular}

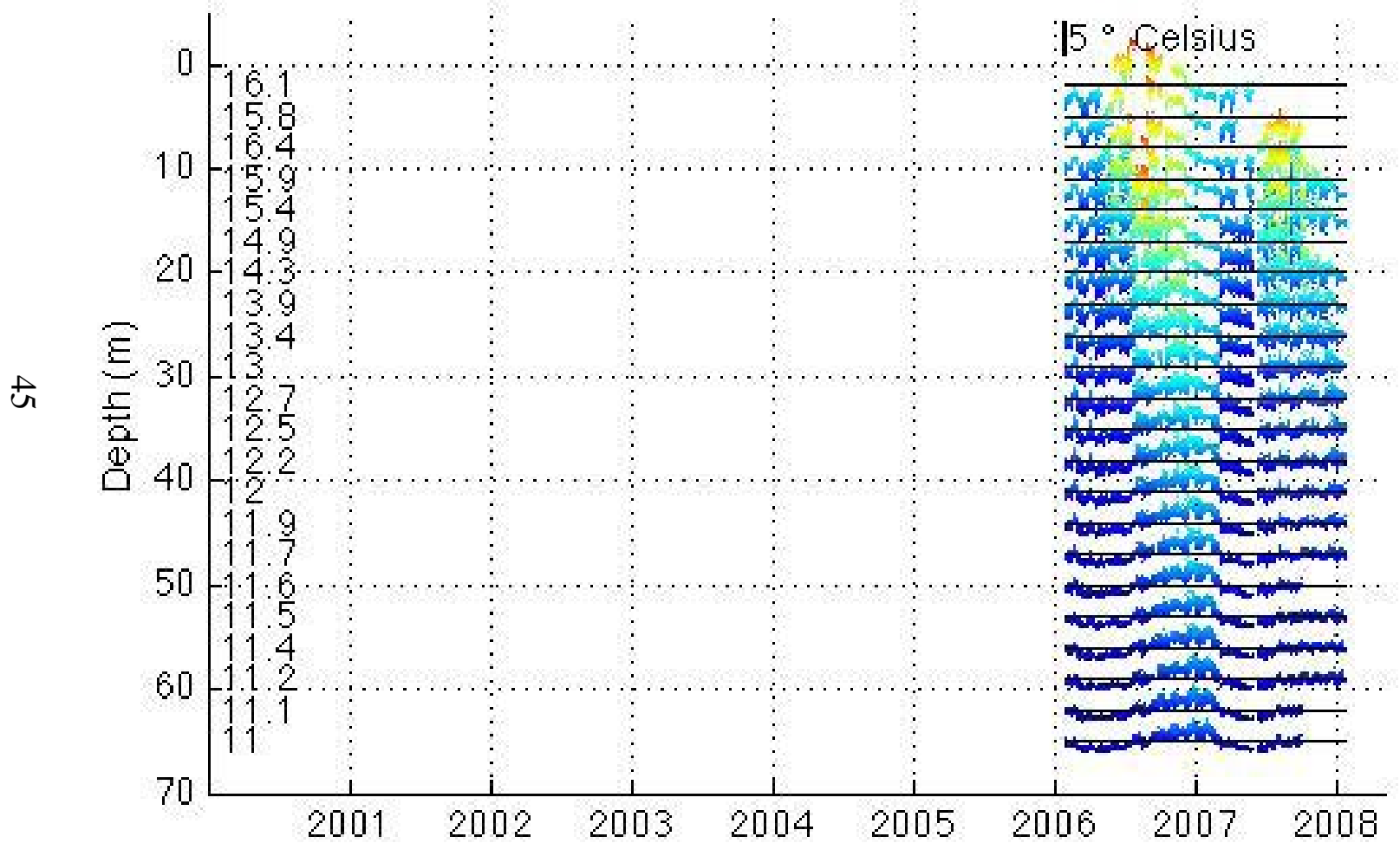

Figure B12. Temperature plots from thermistor TG at Site AG. 
